University of Nebraska - Lincoln

DigitalCommons@University of Nebraska - Lincoln

$3-5-2020$

\title{
Carnivore population structure across an urbanization gradient: a regional genetic analysis of bobcats in southern California
}

\author{
Julia G. Smith
}

Megan K. Jennings

Erin E. Boydston

Kevin R. Crooks

Holly B. Ernest

See next page for additional authors

Follow this and additional works at: https://digitalcommons.unl.edu/natlpark

Part of the Environmental Education Commons, Environmental Policy Commons, Environmental

Studies Commons, Fire Science and Firefighting Commons, Leisure Studies Commons, Natural Resource Economics Commons, Natural Resources Management and Policy Commons, Nature and Society Relations Commons, Other Environmental Sciences Commons, Physical and Environmental Geography Commons, Public Administration Commons, and the Recreation, Parks and Tourism Administration Commons

This Article is brought to you for free and open access by the National Park Service at DigitalCommons@University of Nebraska - Lincoln. It has been accepted for inclusion in U.S. National Park Service Publications and Papers by an authorized administrator of DigitalCommons@University of Nebraska - Lincoln. 


\section{Authors}

Julia G. Smith, Megan K. Jennings, Erin E. Boydston, Kevin R. Crooks, Holly B. Ernest, Seth Riley, Laurel E. K. Serleys, Shaelynn Sleater-Squires, and Rebecca L. Lewison 


\title{
Carnivore population structure across an urbanization gradient: a regional genetic analysis of bobcats in southern California
}

\author{
Julia G. Smith (D) Megan K. Jennings • Erin E. Boydston • Kevin R. Crooks • \\ Holly B. Ernest • Seth P. D. Riley • Laurel E. K. Serieys - Shaelynn Sleater-Squires • \\ Rebecca L. Lewison
}

Received: 30 April 2019/Accepted: 18 January 2020/Published online: 5 March 2020

U.S. government works are not subject to copyright.

(C) Springer Nature B.V. 2020

\begin{abstract}
Context In human-dominated landscapes, habitat fragmentation and barriers to movement can interrupt gene flow. While often considered at a local extent, regional analyses are also needed to reveal broader landscape-mediated population processes.

Objectives To explore the relationship between patterns of gene flow and fragmentation resulting from urbanization across southern California, we used the bobcat as an indicator species. We assembled data
\end{abstract}

Electronic supplementary material The online version of this article (https://doi.org/10.1007/s10980-020-00971-4) contains supplementary material, which is available to authorized users.

J. G. Smith $(\varangle) \cdot$ M. K. Jennings · R. L. Lewison

Biology Department, San Diego State University,

San Diego, CA, USA

e-mail: Julie.Lilit@gmail.com

M. K. Jennings

e-mail: mjennings@sdsu.edu

R. L. Lewison

e-mail: rlewison@sdsu.edu

E. E. Boydston

PO Box 1256, Blanco, TX 78606, USA

e-mail: Erin.Boydston@gmail.com

K. R. Crooks

Department of Fish, Wildlife, and Conservation Biology,

Colorado State University, Fort Collins,

CO, USA

e-mail: Kevin.Crooks@colostate.edu for a landscape level genetic analysis across southern California from both archived and new samples, including two northern Californian populations for comparison, to identify local and regional areas affected by isolation.

Methods Our regional analyses focused on a dataset of 19 microsatellite loci for 118 individuals and a dataset of 422 individuals genotyped at 11 loci. We examined population genetic structure and examined how pairwise genetic distance of all population clusters aligned with geographic distance. We employed a landscape genetic analysis based on resistance to determine which features of the

\author{
H. B. Ernest \\ Wildlife Genomics and Disease Ecology Ab, Department \\ of Veterinary Sciences and Program in Ecology, \\ University of Wyoming, Laramie, WY, USA \\ e-mail: Holly.Ernest@uwyo.edu \\ S. P. D. Riley \\ National Park Service, Santa Monica Mountains National \\ Recreation Area, Thousand Oaks, CA, USA \\ e-mail: seth_riley@nps.gov \\ L. E. K. Serieys \\ Department of Environmental Studies, University of \\ California Santa Cruz, Santa Cruz, CA, USA \\ e-mail: laurelserieys@gmail.com
}


landscape likely play a role in determining the patterns of genetic structure we observed.

Results Study populations generally exhibited a pattern of isolation by distance and localized areas of genetic isolation. The landscape genetic analysis suggested that, in southern California, these patterns are driven by overall landscape permeability.

Conclusions Although local studies are key to examining the effects of urbanization and habitat fragmentation on populations, we demonstrate the importance of combining local and regional analyses for wide-ranging species to understand and maintain connectivity at local scales, while also improving and establishing sustainable linkages to habitats at the regional scale.

Keywords Landscape connectivity - Landscape genetics - Habitat fragmentation - Isolation by resistance $\cdot$ Microsatellites $\cdot$ Lynx rufus

\section{Introduction}

Landscape connectivity is the degree to which the features of a landscape facilitate or impede movement of organisms among resource patches (Taylor et al. 1993). In human-dominated landscapes, barriers to movement can interrupt gene flow, as demonstrated in multiple taxa (Vandergast et al. 2009; Delaney et al. 2010; Ernest et al. 2014; Barr et al. 2015; Stillfried et al. 2017). This fragmentation can reduce functional connectivity by limiting the movement of organisms among habitat patches, sometimes causing loss of biodiversity in patches isolated from source populations (Soulé et al. 1992; Taylor et al. 1993; Tischendorf and Fahrig 2000; Ruell et al. 2012). When patches of suitable habitat become isolated, affected populations can suffer from genetic drift, inbreeding, loss of

\footnotetext{
L. E. K. Serieys

Institute for Communities and Wildlife in Africa, Biological Sciences, University of Cape Town, Cape Town, South Africa

\section{S. Sleater-Squires}

Department of Ecology and Evolutionary Biology, University of California, Los Angeles, Los Angeles, CA, USA

e-mail: sasleater@ucla.edu
}

genetic diversity, and potential extirpation (Brown and Kodric-Brown 1977; Allendorf 1986; Saccheri et al. 1998; Frankham 2005; Delaney et al. 2010). Urbanization and roadways, in particular, are primary factors causing fragmentation and thereby population isolation, challenging population viability (Riley et al. 2006; Delaney et al. 2010; Haddad et al. 2015).

Although the consequences of loss of connectivity are typically described at a local extent, i.e., at the preserve, city, or county level, regional analyses can also be useful to identify pinch points and areas of management priority, particularly for wide-ranging species (Noss 1983; Turner 1989). Regional monitoring of extirpation or colonization can provide an understanding of important metapopulation dynamics, which can reveal the impacts of habitat fragmentation and inform assessments of landscape connectivity for wildlife populations (Noss 1983; Verboom et al. 1991). While many conservation efforts seek to maintain species diversity within local areas (MacArthur 1965; Crooks et al. 2004), the need to protect and create interconnected habitat patches, facilitating movement despite anthropogenic influences, is recognized as key to establishing viable ecological networks at the regional scale $(\mathrm{Ng}$ et al. 2004; Tammeleht et al. 2010; Joshi et al. 2013).

One approach to evaluate the impacts of fragmented landscapes on wildlife populations is to examine population genetics and gene flow. Maintaining gene flow is a critical component of metapopulation dynamics and persistence of populations threatened by habitat fragmentation (Ernest et al. 2003; Keller and Largiadèr 2003; Epps et al. 2018). Genetic analyses can reveal if a population is isolated, inbred, or if animals have dispersed to or from isolated populations (Tischendorf and Fahrig 2000; Frankham 2005; Ruell et al. 2012). Consequently, genetic data can be used to determine whether habitat fragmentation resulting from urban development is limiting functional connectivity (Frankham 2005). Although next generation genetic markers and analyses, i.e., single nucleotide polymorphisms (SNPs) and whole genome sequencing, are robust approaches to characterizing population structure, many large-scale population analyses still rely on markers such as microsatellites to leverage archived and existing data (Ferchaud et al. 2018; Hunter et al. 2018).

Genetic analyses to assess the impacts of fragmentation, and conversely landscape connectivity, often 
employ focal species (Lambeck 1997; Crooks 2002). Because of their ability to disperse long distances (Knick and Bailey 1986) and their capacity to use habitat near urban areas, bobcats (Lynx rufus) have been used as a focal species to assess connectivity, particularly in southern California, where wildlands with suitable bobcat habitat abut large metropolitan areas in the U.S. (Crooks 2002; Ordeñana et al. 2010; Ruell et al. 2012; Lee et al. 2012; Poessel et al. 2014).

As habitat generalists in a biodiversity hotspot, bobcats can persist in a multitude of habitats in southern California. However, bobcat habitat has been increasingly fragmented with urban, agricultural, military, and road development (Hunter et al. 2003; Riley et al. 2006; Ruell et al. 2009, 2012; Burdett et al. 2010; Poessel et al. 2014; Serieys et al. 2015b). Prior research has documented that bobcat populations are negatively affected by barriers to movement which reduce gene flow within areas of southern California, despite their ability to persist within small habitat fragments (Riley et al. 2006; Lee et al. 2012; Serieys et al. 2015b). Southern California exhibits a gradient of urbanization from north to south, with the highest density of development in the Los Angeles metropoli$\tan$ area which declines as one moves south into the less-urbanized San Diego County, where over $40 \%$ of the land area is in conservation status (Zoutendyk et al. 2013). There is also a west to east gradient of development which ranges from the more densely populated areas along the coast in the west to the more intact and preserved areas in the east. Although bobcats are widespread throughout this region, they often lack the ability to disperse among isolated populations which may lead to bottlenecks and lower genetic diversity, similar to the deleterious effects seen in genetically depauperate mountain lion (Puma concolor) populations in the region (Riley et al. 2014; Ernest et al. 2014; Gustafson et al. 2019).

To examine landscape connectivity and associated landscape features across southern California, we combined bobcat genetic data collected from three research efforts in the region, as well as data from two studies from northern California for comparison (Riley et al. 2006; Ruell et al. 2012; Lee et al. 2012; Serieys et al. 2015b). By compiling data from multiple studies, our analysis evaluates functional connectivity in coastal southern California identifying existing patterns of bobcat population structure as well as the landscape features that have led to observed differentiation. This comprehensive landscape genetic analysis provides insight into regional dispersal and local movement patterns of a wide-ranging species and the degree of connectivity across a gradient of urbanization and habitat fragmentation in the coastal southern California region.

\section{Methods}

We compiled a regional genetic dataset collected from 1992-2017, combining archived microsatellite data from three coastal southern California regions as well as from two northern California areas for comparison. In coastal southern California, data were combined from (Fig. 1): Ventura and Los Angeles Counties (LA) from 1996-2015 (Riley et al. 2006; Serieys et al. 2015b; Sleater-Squires 2016), Orange County (OC) from 2002-2009 (Lyren et al. 2006; Ruell et al. 2009; Lee et al. 2012), and San Diego (SD) from 2006-2012 (unpublished data). The two northern California comparison groups were from Golden Gate National Recreation Area (GG) from 1992-1995 (Riley et al. 2004; Riley 2006), and a current study in San Jose (SJ) with bobcats captured in 2017 (Serieys et al. unpublished data). We also included more recently collected samples from SD (2011-2016) and OC (2010-2015), increasing the sample size for those two areas.

Study areas and sample compilation

Archived microsatellite data from a total of 596 bobcats were collected from LA $(n=397)$, OC $(\mathrm{n}=125)$, and $\mathrm{SD}(\mathrm{n}=74)$ from previously published studies conducted between 1996-2015 (Lyren et al. 2006; Riley et al. 2006; Ruell et al. 2009; Lee et al. 2012; Serieys et al. 2015b; Sleater-Squires 2016). To this sample, we added 19 additional samples from OC and 13 from SD. We also included archived data from GG $(n=13)$ and new samples from SJ $(n=17)$ for a total of 658. In each of the study areas, samples of blood, tissue, buccal swabs, or scat were obtained through live capture and opportunistic carcass and scat collection. Because the temporal scale of the data spanned multiple bobcat generations, we removed individuals that represented known events that influenced genetic diversity, i.e., the mange outbreak in LA in 2002-2003 (Serieys et al. 2015a) in a portion of the analyses (described below in "Population Structure 


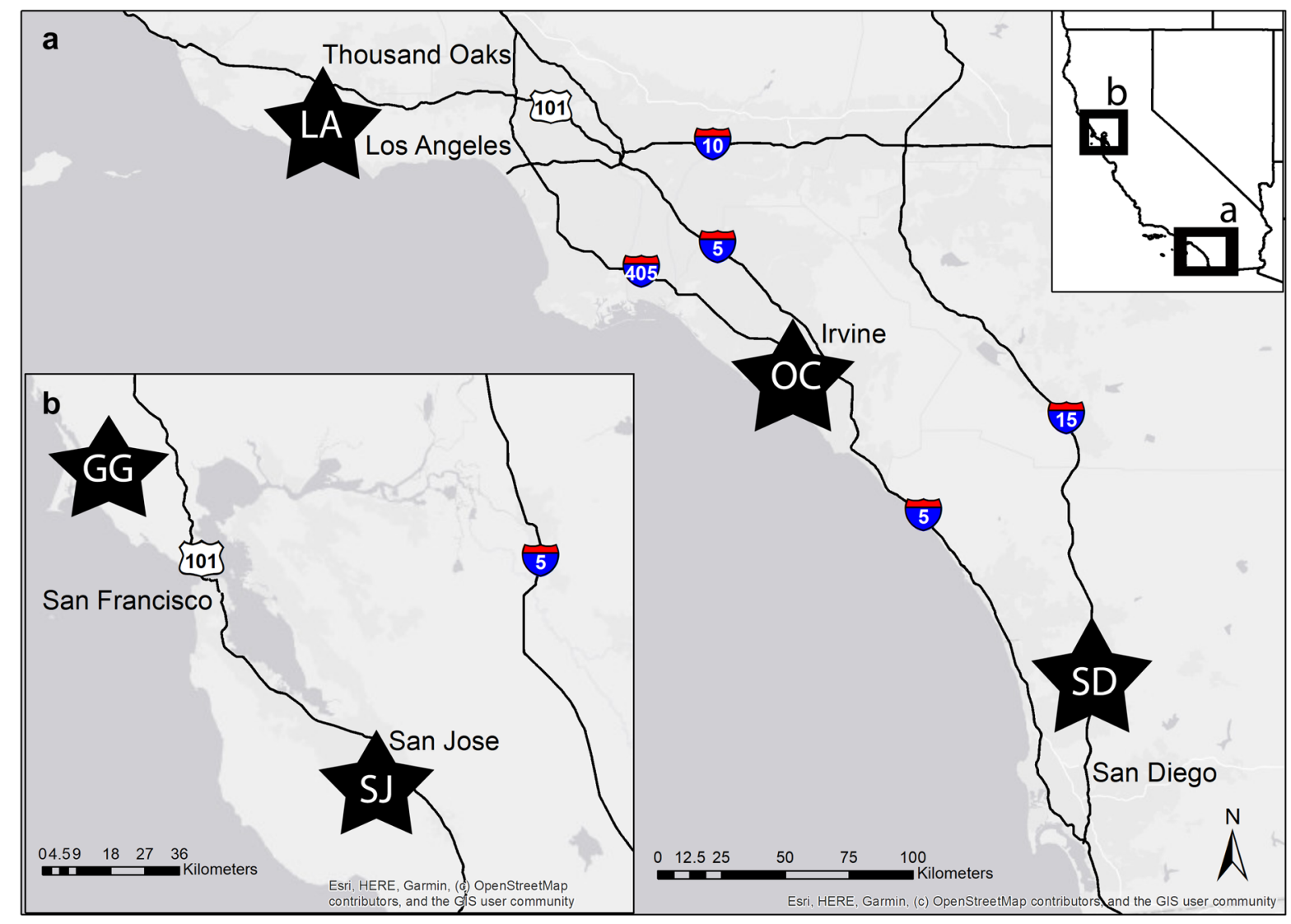

Fig. 1 Map of study areas denoted by black stars with major roadways and city names for context. In northern California a GG (Riley 2006) and SJ, and in southern California b LA (Riley et al. 2006; Serieys et al. 2015a, b), OC (Lee et al. 2012), and SD

and Relationship Analysis" subsection) to explore the influence on our results both with and without these individuals.

The LA study site is centered around the Santa Monica Mountains National Recreation Area (SMMNRA; $623.6 \mathrm{~km}^{2}$ ), which is influenced by two heavily trafficked, eight-lane and larger freeways, US101 and Interstate (I)-405, as well as one smaller but busy six-lane State Route (SR)-23 (Riley et al. 2006; Serieys et al. 2015b). Although SMMNRA itself is a large tract of relatively undisturbed habitat, much of the surrounding area is commercial and residential developments. The OC study site, situated between LA and SD along the southern California coast, is also constrained by development and roadways with the highest intensity of isolation along the coast in the San Joaquin Hills west of I-5 and I-405 (Lee et al. 2012). OC's fragmentation by major roadways has been more recent than that of LA; the LA freeways have been a barrier for approximately sixty to seventy years (US101 completed in 1949 and Interstate (I)-405 in 1962), in contrast to OC where only one freeway (I-5) has existed for that long (completed 1958; Kozakiewicz et al. 2020). The southernmost study site was SD where samples were collected on Marine Corps Base Camp Pendleton, a large expanse of natural habitat north of the SD metropolitan area, Los Peñasquitos Canyon, an urban canyon in central coastal SD, portions of the Cleveland National forest in central SD near the town of Ramona, CA, and east in the San Felipe Valley Wildlife Area at the western edge of the Anza Borrego desert. All sampled bobcats from GG were captured in the Olema Valley area of Marin County (Riley 2006). Samples from SJ were collected from individuals captured in the Coyote Valley in Santa Clara County, an area characterized by a mixed of natural and altered lands, including orchard agricultural fields (Serieys et al. unpublished data). 
Validation and data preparation

A challenge when analyzing microsatellites compiled from various sources is the need for an adequate number of common microsatellite loci among studies in order to have adequate resolution to assess genetic variability (Moran et al. 2006). Additionally, different datasets differ in their absolute sizing of microsatellite alleles (Moran et al. 2006; Ellis et al. 2011). Because microsatellite size estimates, and thus allele designation, can only be compared when prepared by the same protocol and measured by the same instrument, we conducted a validation analysis on a subsample of the data to standardize genotypes across the labs in which the samples were originally processed (de Valk et al. 2009).

The validation subsample was selected such that all alleles from the original data were represented (excluding rare alleles $<5 \%$ ) and allele frequencies of the subsamples were similar to the full datasets from each region (within 6\%). The validation analysis ( $n=61,20$ each for LA and OC, with 21 for SD) was run at the University of California, Los Angeles (UCLA) in 2017 using 19 microsatellite loci (Table S1). In order to reduce variation among laboratories, DNA from all 61 validation individuals was freshly extracted from tissue and blood using QIAGEN DNeasy Blood and Tissue kits (QIAGEN, Valencia, CA, USA) according to the manufacturer's instructions.

All microsatellite genotypes were obtained by polymerase chain reaction (PCR) amplification methods adapted from Boutin-Ganache et al. (2001) using QIAGEN Multiplex PCR Kits (QIAGEN, Valencia, CA, USA; for further details please refer to Appendix 1 in the supplemental material). Because the original studies from which we compiled genotypes did not use identical suites of microsatellite loci, we created one dataset, the 11 loci dataset $(n=422)$ that included all samples with 11 loci and $>67 \%$ of genotypes successfully scored, which excluded 174 of our original 596 archived samples (not including the 62 novel samples that were not analyzed at all loci), and a second, the 19 loci dataset $(\mathrm{n}=118)$, which included all samples where $>67 \%$ of the genotypes were successfully scored at 19 loci.

The data were initially checked for genotyping error due to null alleles and allelic drop-out in Microchecker v. 2.2.3 (Van Oosterhout et al. 2004).
Analyses were conducted in R v. 3.5.1 (R Core Team 2018) unless stated otherwise. Hardy-Weinberg equilibrium probabilities, the number of alleles $\left(\mathrm{N}_{\mathrm{a}}\right)$ per locus, allelic richness, observed heterozygosity, and the proportion of unique alleles for each locus, as well as linkage disequilibrium (LD) between each locus pair were all calculated using the package strataG (Archer et al. 2017).

Out of the original 61 individuals used for validation, 50 had at least $67 \%$ of their loci amplify: 16 for LA, 15 for OC, and 19 for SD. Generally, scoring practices were similar and consistent among all labs. To standardize genotypes, we primarily corrected for size shifts and variation in allele scoring among observers. In many cases, there were consistent size shifts for each locus among all samples within a study site that could be corrected by adding or subtracting base pairs to standardize genotypes. Inconsistencies and standardization errors occurred more often for alleles on the far ends of a locus' range. These alleles can potentially drift out of their designated bins, resulting in misscalls (Ellis et al. 2011). This was dealt with by adjusting correction factors at the ends of a locus' allelic range, typically by adding or subtracting 1-2 base pairs to the size shift correction. For example, locus FCA 023 in SD had a correction factor of 17 except for the two smallest alleles, 142 and 144 which were corrected with a 15 base pair adjustment. Out of the 14 loci that were shared between all three study areas, 13 had clean shifts after errors for the original dataset were cleaned and when certain errors were corrected for as described above. The only locus that did not have a clean shift with a correctable error was FCA077, which may have been due to prior PCR misamplification. This locus was therefore excluded from the validation.

Microchecker (Van Oosterhout et al. 2004) indicated that there was no evidence of stuttering or allelic dropout in the 11 loci dataset, but there was evidence of two null alleles in the 13 loci originally evaluated (at loci FCA 045 and FCA 090), which were eliminated from further analyses, leaving 11 loci for population structure analysis. In the 19 loci dataset there was no evidence of stuttering or allelic dropout, or of null alleles in the 19 loci (Van Oosterhout et al. 2004). In both datasets, evidence of linkage disequilibrium (LD) was found in each previously published study area. However, because none of the same pairs of loci in LD occurred across all study areas, we did 
not eliminate any loci from our analysis due to LD. In the 11 loci dataset, five (out of 11 total) loci differed from Hardy Weinberg equilibrium (HWE) in LA, four in OC, two in SD, none in GG, and one in SJ (Tables 1 \& S2). In the 19 loci dataset, there were five loci in LA (out of 19 total) that significantly differed from HWE, three in $\mathrm{OC}$, none in $\mathrm{SD}$, one in GG, and three in SJ (Tables $1 \&$ S4). Because no loci differed from HWE across all five sub-populations in either dataset, we assumed all sub-populations to be in HWE. Relatedness was tested in ML-RELATE (Kalinowski et al. 2006) among all individuals within each population in the 19 loci dataset.

Population structure and relationship analysis

For both the 11 and 19 loci datasets, we calculated the population differentiation statistic for genetic diversity, $D_{\text {est }}$ (Jost's D; Jost 2008) and all respective p-values (Tables S3 \& S5). We evaluated population structure using two programs, STRUCTURE and discriminant function analysis of principal components (DAPC), to compare and contrast population structuring and assignments. Using STRUCTURE v. 2.3.4 (Pritchard et al. 2000), which uses a Bayesian clustering algorithm to delineate populations, we ran each simulation for $5.0 \times 10^{5} \mathrm{MCMC}$ iterations after a $5.0 \times 10^{4}$ burn-in in an admixture model with putative populations as LOCPRIOR based on broad study area assignments (LA, OC, SD, GG, and SJ). Genetic population clusters $(\mathrm{K})$ were assessed from $\mathrm{K}=1-10$, three times per $\mathrm{K}$ value. We used STRUCTURE Harvester (Earl and vonHoldt 2012) to calculate $\Delta \mathrm{K}$ (Evanno et al. 2005) and $\mathrm{LnP}(\mathrm{K})$ to determine $\mathrm{K}$, or the number of subpopulations (Evanno et al. 2005).

We performed a DAPC using the adegenet package (Jombart 2008), which employs a principal component analysis (PCA) approach to identify population structure and minimize within group variation (Jombart et al. 2010). The resulting principal component scores are then input into a discriminant analysis which identifies among group variance. In contrast to STRUCTURE, DAPC does not require populations to be in HWE and is more capable of identifying weak and hierarchical population structure (Jombart et al. 2010). We determined the number of principal components to retain after model validation of correctly assigned individuals to clusters using cross-validation. Because of lack of convergence of K-means clustering with the 11 loci dataset and the smaller sample sizes of the 19 loci dataset, we used sampling locations as a prior for DAPC analyses. For the 11 loci analysis, we performed our DAPC based on population structuring

Table 1 Microsatellite summary statistics by study area

\begin{tabular}{|c|c|c|c|c|}
\hline Study area & Number of samples & $\begin{array}{l}\text { Number of alleles } \\
\text { averaged across loci }\end{array}$ & $\begin{array}{l}\text { Proportion of unique } \\
\text { alleles averaged } \\
\text { across loci }\end{array}$ & $\begin{array}{l}\text { Average } \\
\text { heterozygosity } \\
\text { across loci }\end{array}$ \\
\hline \multicolumn{5}{|l|}{11 loci } \\
\hline GG & 12 & 4.27 & 0.17 & 0.68 \\
\hline LA & 196 & 6.91 & 0.03 & 0.70 \\
\hline $\mathrm{OC}$ & 124 & 7.73 & 0.05 & 0.72 \\
\hline SD & 73 & 7.27 & 0.05 & 0.75 \\
\hline SJ & 17 & 5.55 & 0.13 & 0.73 \\
\hline \multicolumn{5}{|l|}{19 loci } \\
\hline GG & 13 & 4.26 & 0.19 & 0.64 \\
\hline LA & 18 & 5.42 & 0.20 & 0.65 \\
\hline $\mathrm{OC}$ & 38 & 6.53 & 0.09 & 0.68 \\
\hline SD & 32 & 6.79 & 0.13 & 0.74 \\
\hline SJ & 17 & 6 & 0.14 & 0.73 \\
\hline
\end{tabular}

11 loci $(\mathrm{n}=422)$ and 19 loci $(\mathrm{n}=118)$ dataset summary per population; Golden Gate National Recreation Area (GG), Los Angeles Counties (LA), Orange County (OC), San Diego (SD), and San Jose (SJ) 
patterns established in the published literature (Riley et al. 2006; Ruell et al. 2012; Lee et al. 2012; Serieys et al. 2015b). This included smaller populations in LA separated by US101 (referred to as N101 and S101) as well as a split in the OC region delineating two separate populations on either side of I-5, (referred to as OC inland (OCI) and OC coastal (OCC)). For the LA region, we ran analyses both with and without individuals sampled before and during the mange epizootic in LA as well as after the mange-related genetic bottleneck (Serieys et al. 2015a). The inclusion of individuals both before and after the mange bottleneck produced similar results, but we present analyses with post-mange individuals for clarity. STRUCTURE plots were edited using STRUCTURE PLOT v2.0 (Ramasamy et al. 2014). To explore the population-level relationship between genetic and geographic distances and test for isolation by distance among bobcat populations, we assessed pairwise genetic distance, measured as $D_{\text {est }}$ (Jost 2008), in relation to Euclidean distance using a maximum likelihood population-effects (MLPE) model in the ResistanceGA package (Peterman 2018) and calculated $95 \%$ confidence intervals with the lme4 package (Bates et al. 2015). Finally, to further examine the relationship between six subpopulations (GG, SJ, LA, OCC, OCI, and SD) for the 11 loci dataset, we used a graph theoretic approach as described in Dyer and Nason (2004), implemented in gstudio and popgraph in $\mathrm{R}$ (Dyer 2009).

\section{Landscape resistance analysis}

To explore whether anthropogenic landscape features were linked to gene flow for bobcats, we conducted a landscape genetic analysis using the 19 loci dataset, testing resistance models within each of four southern California subpopulations (LA, OCC, OCI, and SD), as well as for all individuals sampled in the southern California study areas $(n=88)$. Using a hierarchical approach, we tested five related landscape variables to investigate the role of road density, traffic density, other metrics of urban areas (distance to urban area, percent of impervious surface), or a composite metric of urbanization and naturalness explained the patterns of genetic variance we observed. We calculated road density of all roads ranging from freeways to residential streets measured as $\mathrm{km}$ of road per $\mathrm{km}^{2}$ using Open Street Map data for California ("OpenStreetMap"
2014). Traffic density data, represented as distance decayed annual average daily traffic (AADT), were obtained from MacDonald (2017). Distance to urban was calculated as the Euclidean distance to the edge of any urban land uses, not including roads, based on land-use data from the California Department of Conservation. Percent impervious surface estimates generated from the National Land Cover Database (Jin et al. 2013) represented the combined influence of both roads and developed areas. Finally, in addition to considering potential barriers to gene flow, we evaluated a landscape permeability surface (The Nature Conservancy, unpublished data) which ranged from low permeability in more intensely developed areas to high permeability through intact natural areas. This surface was developed using a combination of natural land cover classes (Jin et al. 2013), housing density, road and rail data, and energy development data of local $(3 \mathrm{~km})$ movement potential based on resistance values assigned to land cover and housing density classes as well as roads and energy infrastructure such as power transmission lines and gas pipelines. We selected or generated these continuous variables to explore different aspects of urbanization that may affect bobcats within our study region.

We employed a multiscale approach similar to Zeller et al. (2014), evaluating the variables described above at a range of biologically relevant spatial scales ranging from daily movement distances to home range size ( $\sim 2 \mathrm{~km}^{2}$ for females; Crooks 2002; Riley et al. 2003), and with consideration of the likely perception distance of bobcats in the region given previously observed dispersal events of up to $16-20 \mathrm{~km}$. Each potential resistance surface was smoothed at these spatial scales $(170 \mathrm{~m}, 275 \mathrm{~m}, 519 \mathrm{~m}, 1000 \mathrm{~m}$, $2000 \mathrm{~m}, 3000 \mathrm{~m}$, and $4000 \mathrm{~m}$ ) using the smoothie package v 1.0-1 (Gilleland 2013). We then transformed these scaled surfaces using seven functions and rescaled each to range from 1-100 (Fig. S1). Positive or negative transformation functions were used to represent increasing or decreasing resistance with increasing values of that variable. We also used the inverse Ricker transformation to account for variables that might have a low resistance at moderate values.

Following the approach described in Zeller et al. (2017), we calculated genetic (Nei's distance and $D_{P S}$ ) (Bowcock et al. 1994) and geographic distances. We then compared the different scales, transformations, 
and resistance surfaces developed for each variable using a univariate linear mixed effects model and a MLPE to account for the pairwise nature of the data using a combination of code from the ResistanceGA (Peterman 2018), gdistance (van Etten 2018), and lme4 (Bates et al. 2015) packages in R. We selected the best scale and transformation for each resistance surface using Akaike's Information Criterion, corrected for small sample size (AICc; Burnham and Anderson 2004) and then ranked each surface by AICc to determine which had the greatest explanatory power in describing the observed patterns of genetic variation across all of southern California and within the four subpopulations we tested.

\section{Results}

Population structure and relationship analysis

Using STRUCTURE on the 11 loci data, we found that $\Delta \mathrm{K}=3$ (Fig. 2a) with one population roughly representing LA, the second population including individuals from OCC, and the last population representing a combination of OCI, SD, GG, and SJ. Given the low likelihood that bobcats from the northern California groups (GG and SJ), which are more than $500 \mathrm{~km}$ away and separated by the California's Central Valley and urbanization in the San Francisco Area, represent a single population with bobcats in southern California, we then ran STRUCTURE using the 19 loci dataset. Our initial analyses also found little population differentiation $(\Delta \mathrm{K}=2)$ with one cluster identified as an isolated OCC population and a second cluster composed of all other populations. This strong signal from OCC has been previously documented in bobcats and mule deer (Ruell et al. 2012; Lee et al. 2012; Fraser et al. 2019). To account for this, we ran STRUCTURE without the distinct OCC population to better understand patterns among the remaining study sites. This resulted in $\Delta \mathrm{K}=5$ which reflected subpopulations in (1) LA, (2) SD and most of OCI, (3) GG, and (4) SJ and (5) with OCC as the fifth subpopulation (Fig. 2b).

We then compared the STRUCTURE results to outputs from our DAPC analysis. With the 11 loci dataset, we observed a stepping stone type pattern across most of the region and State (Fig. 3). The LA study area, OCC and GG exhibited the greatest degree of differentiation. In the 19 loci dataset, the differentiation in LA was evident as individuals north and south of Highway 101 were distinct (Fig. 4). In keeping with our previous results from STRUCTURE, OCI and SD overlap, likely reflecting a high degree of gene flow. The pairwise $\mathrm{D}_{\text {est }}$ matrices for both the 11 loci (Table S3) and 19 loci (Table S5) datasets further
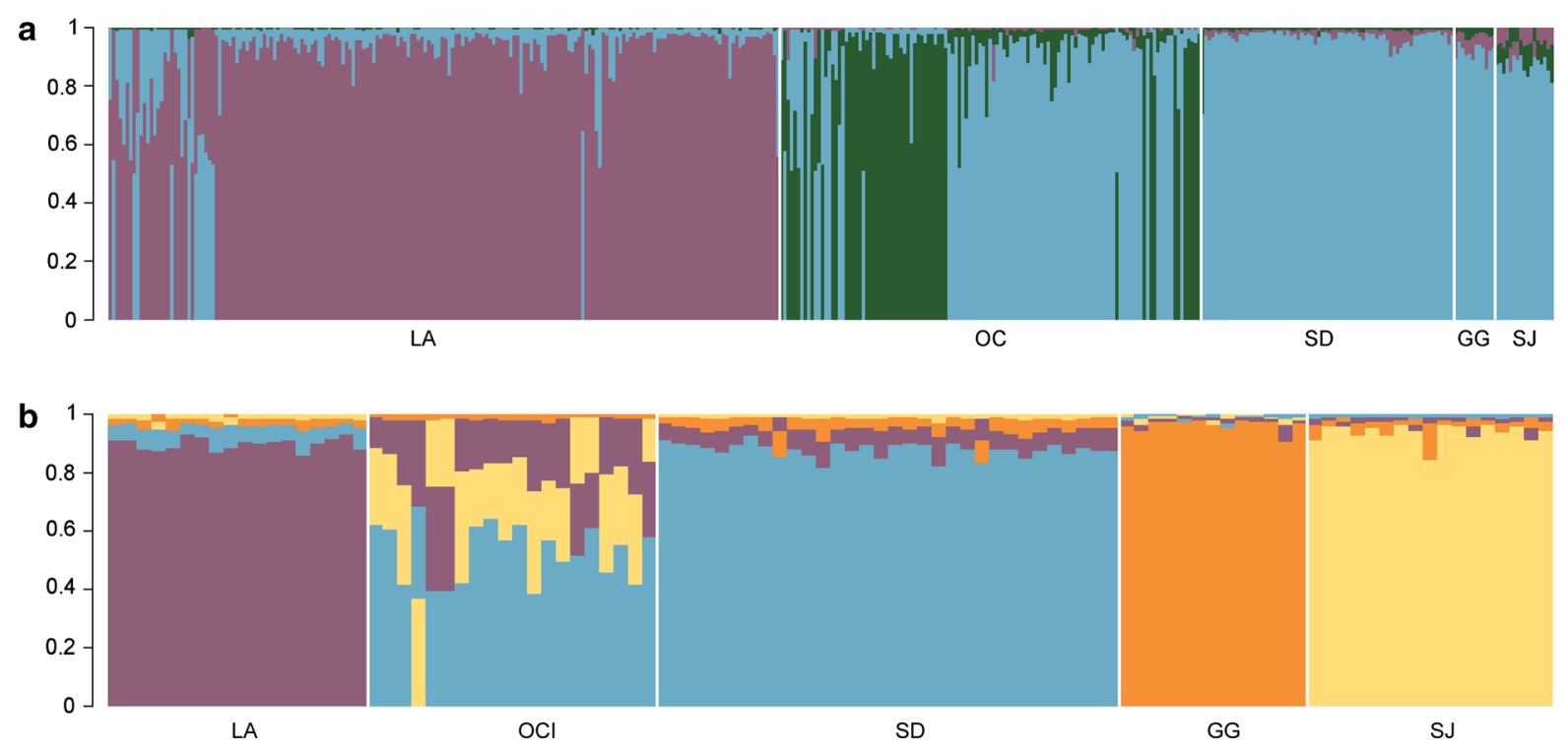

Fig. 2 STRUCTURE plots of California bobcats: a 11 loci dataset $(n=422)$, with $\Delta K=3$. b 19 loci dataset $(n=100)$ with $\Delta K=5$ (OCC not shown) 


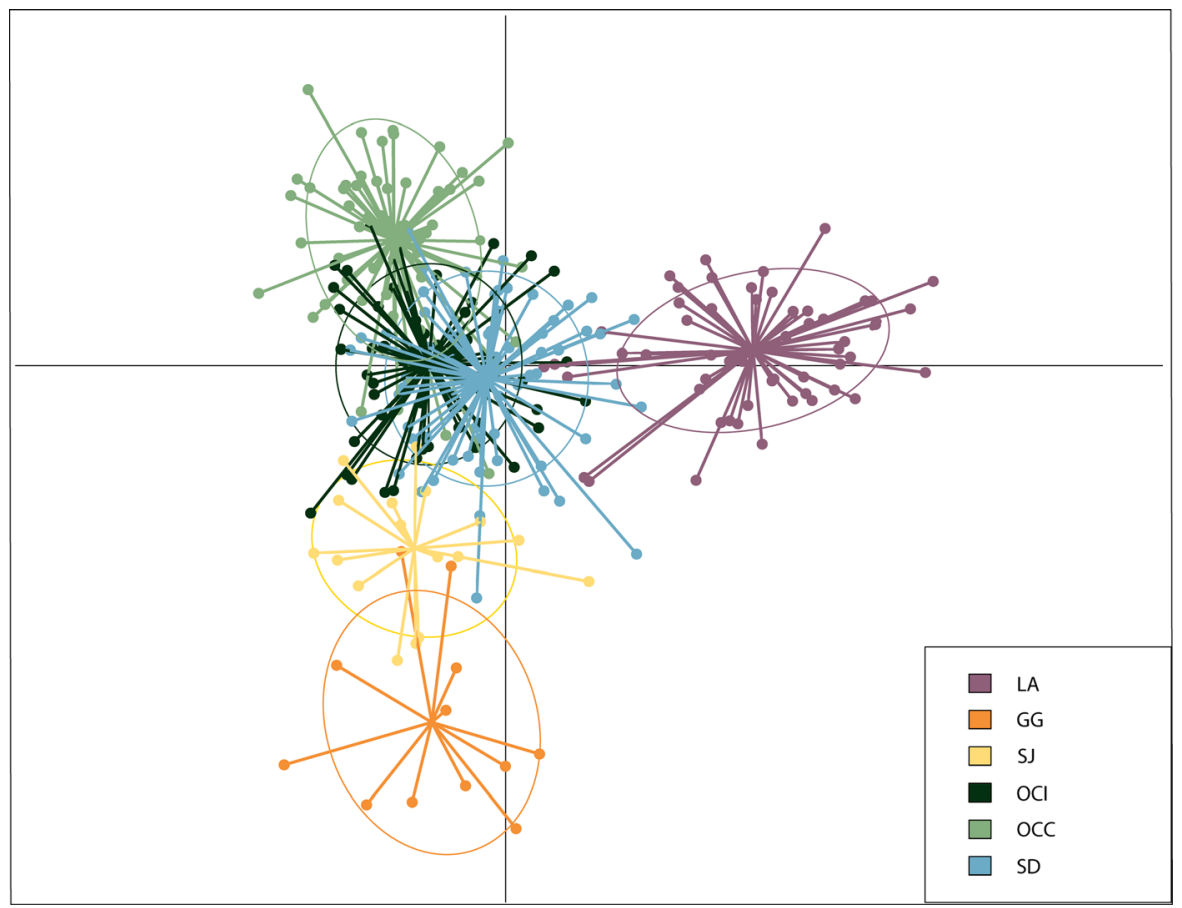

Fig. 3 Results of a priori population clustering of the 11 loci dataset in a discriminant function analysis of principal components (DAPC) scatterplot of population clusters. Each

supported the patterns of hierarchical relationships we observed among study sites from the DAPC analysis. Based on the MLPE model of the relationship between genetic and geographic distances among populations, we did find evidence of isolation by distance in the observed genetic patterns (Fig. 5). Population pairs were focused around two clusters, one representing within-region pairs (i.e., within southern California or northern California), and the other from betweenregion pairs. Although many subpopulation pairs demonstrated relationships keeping with a pattern of isolation by geographic distance, some pairs were less genetically differentiated than expected given their distance (e.g., OCI-SD), whereas others were more differentiated than expected. In both groups, OCC, GG, and N101 generally exhibited greater genetic differentiation than could be explained by geographic distance alone (Fig. 5). Pairwise relatedness among individuals within populations ranged from 0.01 $(\mathrm{S} 101, \mathrm{SE}=0.0071)$ to $0.08(\mathrm{~N} 101, \mathrm{SE}=0.0214)$. When we employed a graph theoretic approach to further explore relationships between subpopulations with the 11 loci dataset, we found similar patterns to dot represents an individual and the color, a labeled population. Ellipses summarize the cloud of points with bivariate normal distributions

our DAPC analysis, and gained a better understanding of the connectivity and relationships among these populations (Fig. S2).

Landscape resistance analysis

We found that regardless of genetic distance measure used, permeability, a landscape feature which captures both built and natural landscape features, was the strongest predictor of genetic differences and variation across the southern California landscape for bobcats (Table S6; Fig. 6). An inverse Ricker transformation of permeability at a $2000-\mathrm{m}$ scale was the strongest predictor of the observed patterns of genetic variation, indicating that bobcats were influenced at a coarse scale or neighborhood by low resistance at moderate values of permeability and high resistance at either low or high levels of permeability. However, we did not have many data points or paths between points represented at the highest levels of permeability given the coastal urban nature of our study sites. Through our model testing, we found that resistance transformations demonstrating avoidance of anthropogenic 


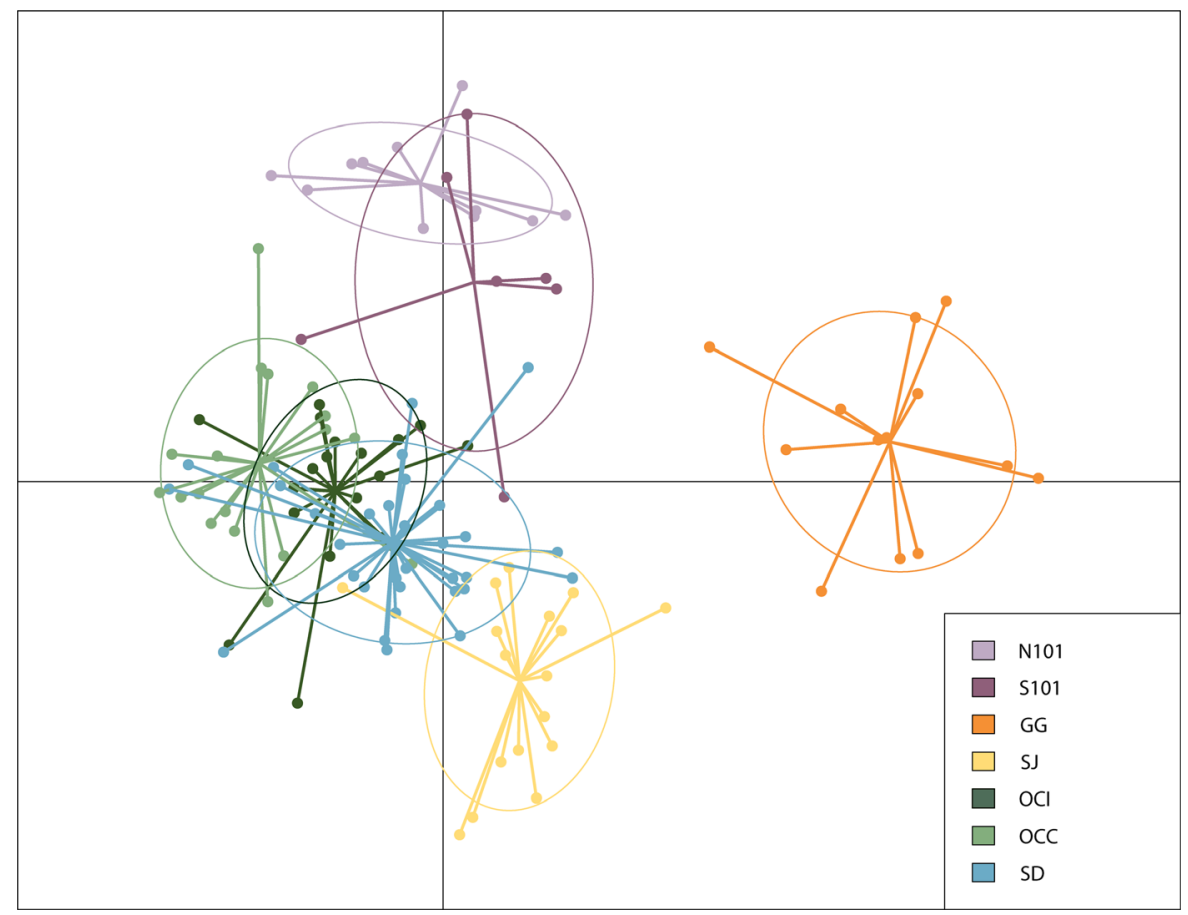

Fig. 4 Results of a priori population clustering of the 19 loci dataset in a discriminant function analysis of principal components (DAPC) scatterplot of population clusters. Each dot

features (i.e., impervious surface and roads) were important for describing genetic distance, but that the combination of the natural component of the landscape with these anthropogenic features represented by the permeability surface greatly enhanced model prediction. Given that the impervious surface variable was consistently a better predictor of genetic patterns than the tested road metrics, it appears that the combination of all three landscape features-use of intact natural areas and avoidance of developed lands as well as roadways - are critical in driving patterns of genetic variation among bobcat populations in southern California.

In comparison, our analysis of landscape resistance within the four southern California subpopulations (LA, OCC, OCI, and SD) revealed differing landscape features and scales that likely affect genetic differentiation at the local level (Table S7). In LA, Euclidean distance was the best predictor of genetic differentiation with individuals farther apart being more genetically distinct. In OCC, road density at a 2000-m scale and either a positive monomolecular concave (based on $\mathrm{D}_{\mathrm{PS}}$ ) or inverse Ricker transformation (based on represents an individual and the color, a labeled population. Ellipses summarize the cloud of points with bivariate normal distributions

Nei's distance) performed best. This would suggest that in OCC, where bobcats were genetically distinct from the other subpopulations, that roads influence individuals at a coarse neighborhood either at a threshold where resistance is high once road density increases to a certain limit, or that resistance is high at both low and high road densities and low at moderate road densities. Similar to the full southern California analysis, the performance of the inverse Ricker transformation may be affected by a limited number of samples in areas of low road density in the highly constrained region of coastal Orange County. In both OCI and SD, permeability was the selected predictor, just as in our analysis of all southern California individuals, although at different scales and transformations. OCI bobcats appeared to be influenced at a coarse scale of permeability $(2000 \mathrm{~m})$ but resistance appeared to be greatest when permeability was low. This is perhaps because the most permeable lands in this area are in the steep, rugged, Santa Ana Mountains, which bobcats may opt to skirt the edges of, rather than cross directly. In SD, bobcats appeared to respond to permeability at a finer neighborhood 
$(170 \mathrm{~m})$, also with the inverse Ricker transformation observed across all southern California individuals.

\section{Discussion}

Using bobcats as an indicator species, our analytical approaches identified localized areas of limited or impeded landscape connectivity across southern California as evidenced by genetic isolation. The strongest signals of genetic isolation came from the most constrained urban areas in the region in LA and OCC. Our DAPC results affirmed evidence of isolation of bobcat populations in Los Angeles identified in published literature (Riley et al. 2006; Serieys et al. 2015 b) that likely resulted from barriers posed by development and the US101. This genetic differentiation may also reflect a population bottleneck caused by a mange outbreak in 2002 (Serieys et al. 2015b), which may have affected the genetic variation of our samples. The genetic differentiation of OCC around the San Joaquin Hills was most apparent in our STRUCTURE analyses, consistent with prior studies (Ruell et al. 2012; Lee et al. 2012), which suggest a

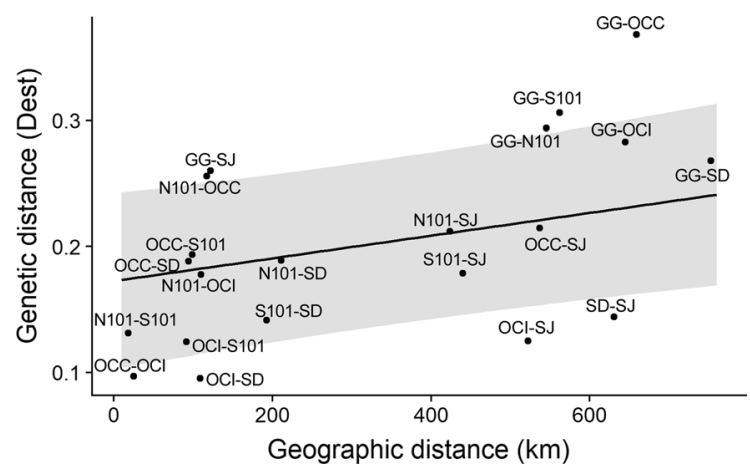

Fig. 5 Isolation by distance (IBD) plot, illustrating the relationship between pairwise genetic (measured as Dest) and geographic (measured as Euclidean) distances among the seven sampled California bobcat populations using the 19 loci dataset (SD—San Diego; OCC—Orange County coastal; OCI—Orange County inland; S101-south of US101 in LA; N101-north of US 101 in LA; SJ-San Jose; GG-Golden Gate), using a maximum likelihood population-effects (MLPE) model in the ResistanceGA package (Peterman 2018). Line represents the predicted relationship between genetic and geographic distance, suggesting a general pattern of IBD, with shading of the $95 \%$ confidence interval. Pairs on the left side of the graph are within region comparisons and on the right side are among region comparisons. Points above the line represent more genetic differentiation than expected from geographic distance population division driven by the I-5 freeway. This pattern of fragmentation west of I-5 has been documented in other species including southern mule deer (Odocoileus hemionus fuliginatus; Fraser et al. 2019) and cactus wren (Campylorhynchus brunneicapillus; Barr et al. 2015). As expected, we also observed higher differentiation in GG, likely due to fragmentation from urban isolation and roadways, similar to the differentiation observed in OCC. We found that Euclidean distance was not an informative predictor for gene flow across the landscape similar to bobcats in New Hampshire (Litvaitis et al. 2015).

While our analyses confirmed previously identified regional barriers to landscape connectivity, we also identified areas of connectivity not previously reported. We observed a high degree of gene flow between SD, OCI, and even SJ, despite its geographic distance from these southern California populations. Although considered part of the larger San Francisco Bay Area metropolis, the SJ study area lies to the southeast of the urban zone, with putatively permeable habitat linking the area to southern California along the central coast range. Further research would be required to identify the landscape linkages that foster bobcat movement and gene flow between northern and southern California.

Our regional study of samples within the state of California can be further contextualized at a continental scale by comparing our results with a previous study of bobcat genetics across North America which also included samples from our OC study site (Reding et al. 2012). Of 1,700 samples from the bobcat's range in North America, only southern California and southern Florida formed small, distinct genetic clusters among the 10 populations identified using microsatellite data (Reding et al. 2012). This national pattern of isolation for southern California bobcats mirrors findings for mountain lion populations in LA which were found to have some of the lowest genetic diversity nationally, second only to the Florida panther (Puma concolor coryi, Roelke et al. 1993; Riley et al. 2014). Similar genetic population structuring and lack of genetic diversity within portions of southern California were also observed for mountain lions in a regional-scale analysis that encompassed the states of California and Nevada (Gustafson et al. 2019).

The landscape analysis we conducted provided insight into the mechanisms of isolation driving observed patterns of genetic differentiation both 


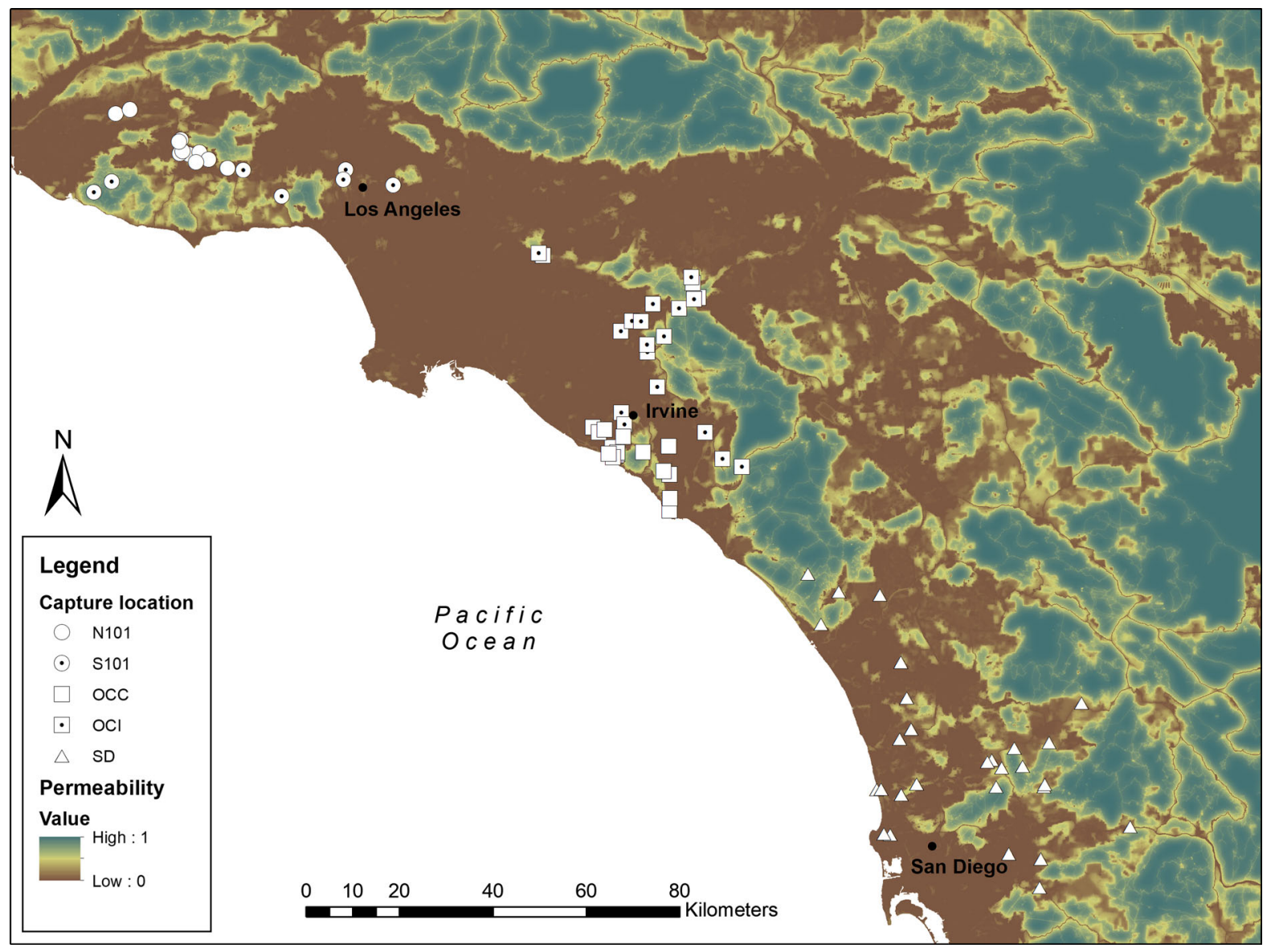

Fig. 6 Map of landscape resistance analysis results depicting permeability, which best explained the genetic distance of bobcats sampled in southern California at an inverse Ricker transformation at a $2000 \mathrm{~m}$ scale. Brown indicates areas of low permeability across the landscape and blue, areas of high permeability. Southern California bobcats $(n=88)$ sampling locations are partitioned by subpopulation; in LA, north (N101; circle) and south (S101; circle with dot) of US101, west (OCC; white square) and east (OCI; white square with dot) of the I-5 in $\mathrm{OC}$, and $\mathrm{SD}(\mathrm{SD}$; triangle) within bobcat subpopulations and at a regional scale across southern California. Our hierarchical approach allowed us to compare individual landscape predictors in a complex and heterogeneous landscape and, although univariate models had relatively low predictive capacity with unexplained variation in the pairwise genetic data, we identified key features that likely affect bobcat gene flow locally and regionally (Table S6). Consistent with prior findings from local-level analyses, (Riley et al. 2006; Ruell et al. 2012; Lee et al. 2012; Serieys et al. 2015b) roads, traffic, and urbanization all appear to be contributing factors leading to population structuring, particularly in the intensely urbanized areas where those features are most prominent. Not surprisingly, within OCC, a subpopulation we found to be substantially genetically distinct, road density best explained this differentiation in an area hemmed in by several large freeways which has previously been noted in local-level analyses (Lee et al. 2012). Interestingly, gene flow in LA, which we also found to be genetically distinct based on our other analyses, was best described by Euclidean distance. This is perhaps because of the smaller sample size in this subpopulation, our inability to separate our N101 and S101 samples for this analysis, and the close proximity of the capture locations for individuals from LA in our 19 loci dataset. However, both within OCI and SD as well as across the region, it 
was the natural features of the landscape such as intact shrublands and riparian areas in combination with these anthropogenic features, represented by a permeability metric, that best explained the observed patterns of genetic distance among southern California bobcats.

The importance of natural landscape features in general, and streams and riparian areas in particular, has also been linked to bobcat presence or dispersal in previous studies (Kozakiewicz et al. 2019; Markovchick-Nicholls et al. 2008). In our study area specifically, permeability was relatively high among the more contiguous habitats where genetic differentiation was lowest, including SD and OCI. The spatial patterns of permeability in these two relatively intact areas may have also affected the scales at which bobcats appear to respond to the surrounding landscape. In OCI, there is a large, highly permeable block of conserved land surrounded by impermeable development which may drive coarse-level responses. In $\mathrm{SD}$, a number of smaller, coastal preserves with moderate to high permeability provide a connection to the highly permeable landscape in the eastern portion of the region and which may affect gene flow at a finer ecological neighborhood. In contrast to the patterns in these two relatively intact areas, permeability was much lower around OCC and LA, where bobcat populations were more isolated and genetically distinct from adjacent populations (Fig. 6). These results are further supported by the MLPE model of the genetic and geographic distance, which indicated a general pattern of isolation by distance within and among our two study regions, but with exceptions to this pattern demonstrated by the most constrained study sites with the lowest degree of permeability in our analysis: GG, OCC, and LA north of US101 (Fig. 5).

To facilitate planning and management for connectivity, wide-ranging carnivores can inform local and regional conservation efforts (Gustafson et al. 2019). Our study and the results of analyses of other species in the region highlight the importance of maintaining connectivity on local scales, while also improving and establishing sustainable linkages to habitats at the regional scale. Roads and development act together as barriers of movement for bobcats; therefore it is not only important to target wildlife crossings to increase road permeability (Rodriguez et al. 1996), but also to conserve undeveloped land abutting such crossings to facilitate their use and maintain landscape-scale permeability $(\mathrm{Ng}$ et al. 2004). Our findings of regional population structure across an impacted landscape and urbanization gradient are critical for understanding how urbanization and subsequent habitat fragmentation result in populationlevel impacts. This regional perspective is particularly important for species sensitive to fragmentation, like bobcats, because landscape-level genetic signals may be difficult to detect with local-level analyses alone (Kozakiewicz et al. 2019). Utilizing population genetic analyses for bobcats and other indicator species as a tool can help gauge how populations are responding to landscape changes due to urbanization, providing important context for future management action and land acquisition.

Acknowledgements We would like to thank W. Peterman and two anonymous reviewers for their edits and code, D. Fraser for assistance with laboratory work and very insightful analysis suggestions, J. Pollinger for his thoughtful assistance in the interpretation of the validation dataset, and R. Wayne for hosting the validation runs in his laboratory. A. Mitelberg and A. Vandergast shared invaluable advice for planning and evaluating the microsatellite dataset. K. Zeller provided code and helpful insights into the landscape genetic analyses. Funding support was provided by the National Science Foundation, Ecology of Infectious Disease Program (NSF-EID 1413925 and 723676), the National Park Service, Peninsula Open Space Trust, San Diego County Fish and Wildlife Advisory Commission (Grant \#2006/07-02) and the San Diego Foundation (Grant \#C-2011-00177). We thank R. Fisher of the U.S. Geological Survey for sharing samples from Orange County and acknowledge the support of U.S. Geological Survey during this project. We thank land management staff from the City of San Diego, County of San Diego, California Department of Fish and Wildlife, California Department of Transportation, and U.S. Forest Service for providing access and support during field research activities. Samples provided by San Diego State University were collected in accordance with approved IACUC animal protocols \#10-09-027L and \#13-08017 and collected under California Department of Fish and Wildlife Scientific Collecting Permit \#SCP-009632. For samples provided by Dr. Laurel Serieys, all animal capture, handling, collaring, and sample collection was approved by the Institutional Animal Care and Use Committee (IACUC) of UCSC (Protocol Seril1701 and Seril1701_a1). Scientific collecting permits were authorized by the California Department of Fish and Wildlife (SCP-13565). 


\section{References}

Allendorf FW (1986) Genetic drift and the loss of alleles versus heterozygosity. Zoo Biol 5:181-190

Archer FI, Adams PE, Schneiders BB (2017) stratag : an r package for manipulating, summarizing and analysing population genetic data. Mol Ecol Resour 17:5-11

Barr KR, Kus BE, Preston KL, Howell S, Perkins E, Vandergast AG (2015) Habitat fragmentation in coastal southern California disrupts genetic connectivity in the cactus wren (Campylorhynchus brunneicapillus). Mol Ecol 24:2349-2363

Bates D, Maechler M, Bolker B, Walker S (2015) Fitting linear mixed-effects models using lme4. J Stat Softw 67:1-48

Boutin-Ganache I, Raposo M, Raymond M, D. C. (2001) M13Tailed primers improve the readability and usability of microsatellite analyses performed with two different allelesizing methods. Biotechniques 31:24-28

Bowcock AM, Ruiz-Linares A, Tomfohrde J, Minch E, Kidd JR, Cavalli-Sforza LL (1994) High resolution of human evolutionary trees with polymorphic microsatellites. Nature 368:455-457

Brown JH, Kodric-Brown A (1977) Turnover rates in insular biogeography: effect of immigration on extinction. Ecology 58:445-449

Burdett CL, Crooks KR, Theobald DM, Wilson KR, Boydston EE, Lyren LM, Fisher RN, Vickers TW, Morrison SA, Boyce WM (2010) Interfacing models of wildlife habitat and human development to predict the future distribution of puma habitat. Ecosphere 1:4

Burnham KP, Anderson DR (2004) Multimodel inference: understanding AIC and BIC in model selection. Sociol Methods Res 33:261-304

Crooks KR (2002) Relative Sensitivities of Mammalian Carnivores to Habitat Fragmentation. Conserv Biol 16:488-502

Crooks KR, Suarez AV, Bolger DT (2004) Avian assemblages along a gradient of urbanization in a highly fragmented landscape. Biol Cons 115:451-462

Delaney KS, Riley SPD, Fisher RN (2010) A rapid, strong, and convergent genetic response to urban habitat fragmentation in four divergent and widespread vertebrates. PLoS ONE $5: 1-11$

de Valk HA, Meis JFGM, Bretagne S, Costa J-M, Lasker BA, Balajee SA, Pasqualotto AC, Anderson MJ, Alcázar-Fuoli L, Mellado E, Klaassen CHW (2009) Interlaboratory reproducibility of a microsatellite-based typing assay for Aspergillus fumigatus through the use of allelic ladders: proof of concept. Clin Microbiol Infect 15:180-187

Dyer RJ (2009) GeneticStudio: a suite of programs for spatial analysis of genetic-marker data. Molecular Ecology Resources 9:110-113

Dyer RJ, Nason JD (2004) Population Graphs: the graph theoretic shape of genetic structure. Mol Ecol 13:1713-1727

Earl DA, vonHoldt BM (2012) STRUCTURE HARVESTER: a website and program for visualizing STRUCTURE output and implementing the Evanno method. Conservation Genetics Resources 4:359-361

Ellis JS, Gilbey J, Armstrong A, Balstad T, Cauwelier E, Cherbonnel C, Consuegra S, Coughlan J, Cross TF, Crozier W, Dillane E, Ensing D, García de Leániz C, García-
Vázquez E, Griffiths AM, Hindar K, Hjorleifsdottir S, Knox D, Machado-Schiaffino G, McGinnity P, Meldrup D, Nielsen EE, Olafsson K, Primmer CR, Prodohl P, Stradmeyer L, Vähä J-P, Verspoor E, Wennevik V, Stevens JR (2011) Microsatellite standardization and evaluation of genotyping error in a large multi-partner research programme for conservation of Atlantic salmon (Salmo salar L.). Genetica 139:353-367

Epps CW, Crowhurst RS, Nickerson BS (2018) Assessing changes in functional connectivity in a desert bighorn sheep metapopulation after two generations. Mol Ecol 27:2334-2346

Ernest HB, Boyce WM, Bleich VC, May B, Stiver SJ, Torres SG (2003) Genetic structure of mountain lion (Puma concolor) populations in California. Conserv Genet 4:353-366

Ernest HB, Vickers TW, Morrison SA, Buchalski MR, Boyce WM (2014) Fractured Genetic Connectivity Threatens a Southern California Puma (Puma concolor) Population. PLoS ONE 9:e107985

Evanno G, Regnaut S, Goudet J (2005) Detecting the number of clusters of individuals using the software structure: a simulation study. Mol Ecol 14:2611-2620

Ferchaud A-L, Laporte M, Perrier C, Bernatchez L (2018) Impact of supplementation on deleterious mutation distribution in an exploited salmonid. Evol Appl 11:1053-1065

Frankham R (2005) Genetics and extinction. Biol Cons 126:131-140

Fraser DL, Ironside K, Wayne RK, Boydston EE (2019) Connectivity of mule deer (Odocoileus hemionus) populations in a highly fragmented urban landscape. Landscape Ecol 34:1097-1115

Gilleland, E. 2013. Two-dimensional kernel smoothing: using the $\mathrm{R}$ package smoothie. NCAR technical note, TN502+STR, pp 17

Gustafson KD, Gagne RB, Vickers TW, Riley SPD, Wilmers CC, Bleich VC, Pierce BM, Kenyon M, Drazenovich TL, Sikich JA, Boyce WM, Ernest HB (2019) Genetic sourcesink dynamics among naturally structured and anthropogenically fragmented puma populations. Conserv Genet 20:215-227

Haddad NM, Brudvig LA, Clobert J, Davies KF, Gonzalez A, Holt RD, Lovejoy TE, Sexton JO, Austin MP, Collins CD, Cook WM, Damschen EI, Ewers RM, Foster BL, Jenkins CN, King AJ, Laurance WF, Levey DJ, Margules CR, Melbourne BA, Nicholls AO, Orrock JL, Song D-X, Townshend JR (2015) Habitat fragmentation and its lasting impact on Earth's ecosystems. Sci Adv 1:e1500052e1500052

Hunter ME, Hoban SM, Bruford MW, Segelbacher G, Bernatchez L (2018) Next-generation conservation genetics and biodiversity monitoring. Evol Appl 11:1029-1034

Hunter RD, Fisher RN, Crooks KR (2003) Landscape-level Connectivity in Coastal Southern California, USA, as Assessed through Carnivore Habitat Suitability. Nat Areas J 23:302-314

Jin S, Yang L, Danielson P, Homer C, Fry J, Xian G (2013) A comprehensive change detection method for updating the National Land Cover Database to circa 2011. Remote Sens Environ 132:159-175

Jombart T (2008) adegenet: a R package for the multivariate analysis of genetic markers. Bioinformatics 24:1403-1405 
Jombart T, Devillard S, Balloux F (2010) Discriminant analysis of principal components: a new method for the analysis of genetically structured populations. BMC Genet 11:94

Joshi A, Vaidyanathan S, Mondol S, Edgaonkar A, Ramakrishnan U (2013) Connectivity of tiger (Panthera tigris) populations in the human-influenced forest mosaic of Central India. PLoS ONE 8:e77980

Jost L (2008) G ST and its relatives do not measure differentiation. Mol Ecol 17:4015-4026

Kalinowski ST, Wagner AP, Taper ML (2006) ML-RELATE: A computer program for maximum likelihood estimation of relatedness and relationship. Mol Ecol Notes 6:576-579

Keller I, Largiadèr CR (2003) Recent habitat fragmentation caused by major roads leads to reduction of gene flow and loss of genetic variability in ground beetles. Proc Biol Sci 270:417-423

Knick ST, Bailey TN (1986) Long-Distance Movements by Two Bobcats from Southeastern Idaho. Am Midl Nat 116:222

Kozakiewicz CP, Burridge CP, Funk WC, Salerno PE, Trumbo DR, Gagne RB, Boydston EE, Fisher RN, Lyren LM, Jennings MK, Riley SPD, Serieys LEK, VandeWoude S, Crooks KR, Carver S (2019) Urbanization reduces genetic connectivity in bobcats (Lynx rufus) at both intra- and interpopulation spatial scales. Mol Ecol 28:5068-5085

Kozakiewicz CP, Burridge CP, Funk WC, Craft ME, Crooks KR, Fisher RN, Fountain-Jones NM, Jennings MK, Kraberger SJ, Lee JS, Lyren LM, Riley SPD, Serieys LEK, VandeWoude S, Carver S (2020) Does the virus cross the road? Viral phylogeographic patterns among bobcat populations reflect a history of urban development. Evol Appl. https://doi.org/10.1111/eva.12927

Lambeck RJ (1997) Focal Species: A multi-species umbrella for nature conservation: Especies Focales: Una Sombrilla Multiespecifica para Conservar la Naturaleza. Conserv Biol 11:849-856

Lee JS, Ruell EW, Boydston EE, Lyren LM, Alonso RS, Troyer JL, Crooks KR, Vandewoude S (2012) Gene flow and pathogen transmission among bobcats (Lynx rufus) in a fragmented urban landscape. Mol Ecol 21:1617-1631

Litvaitis JA, Reed GC, Carroll RP, Litvaitis MK, Tash J, Mahard T, Broman DJA, Callahan C, Ellingwood M (2015) Bobcats (Lynx rufus) as a model organism to investigate the effects of roads on wide-ranging carnivores. Environ Manage 55:1366-1376

Lyren LM, Turschak GM, Ambat ES, Haas CD, Tracey JA, Boydston EE, Hathaway SA, Fisher RN, Crooks KR (2006) Carnivore activity and movement in a Southern California protected area, the North/Central Irvine Ranch. Geological Survey Technical Report, U.S, p 115

MacArthur RH (1965) Patterns of species diversity. Biol Rev 40:510-533

MacDonald B (2017) Gridded traffic density estimates for southern California, 1995-2014: user notes. https://spatial. usc.edu/custom-geospatial-datasets/.

Markovchick-Nicholls L, Regan HM, Deutschman DH, Widyanata A, Martin B, Noreke L, Ann Hunt T (2008) Relationships between human disturbance and wildlife land use in urban habitat fragments. Conserv Biol 22:99-109
Moran P, Teel DJ, LaHood ES, Drake J, Kalinowski S (2006) Standardising multi-laboratory microsatellite data in Pacific salmon: an historical view of the future. Ecol Freshw Fish 15:597-605

Ng SJ, Dole JW, Sauvajot RM, Riley SPD, Valone TJ (2004) Use of highway undercrossings by wildlife in southern California. Biol Cons 115:499-507

Noss RF (1983) A regional landscape approach to maintain diversity. Bioscience 33:700-706

Van Oosterhout C, Hutchinson WF, Wills DPM, Shipley P (2004) MICRO-CHECKER: software for identifying and correcting genotyping errors in microsatellite data. Mol Ecol Notes 4:535-538

OpenStreetMap (2014) https://www.openstreetmap.org.

Ordeñana MA, Crooks KR, Boydston EE, Fisher RN, Lyren LM, Siudyla S, Haas CD, Harris S, Hathaway SA, Turschak GM, Miles AK, Van Vuren DH (2010) Effects of urbanization on carnivore species distribution and richness effects of urbanization on carnivore species distribution and richness. J Mammal 91:1322-1331

Peterman WE (2018) ResistanceGA: an R package for the optimization of resistance surfaces using genetic algorithms. Methods Ecol Evol 9:1638-1647

Poessel SA, Burdett CL, Boydston EE, Lyren LM, Alonso RS, Fisher RN, Crooks KR (2014) Roads influence movement and home ranges of a fragmentation-sensitive carnivore, the bobcat, in an urban landscape. Biol Cons 180:224-232

Pritchard JK, Stephens M, Donnelly P (2000) Inference of population structure using multilocus genotype data. Genetics 155:945-959

R Core Team. (2018) R: A language and environment for statistical computing. R Foundation for Statistical Computing, Vienna, Austria

Ramasamy R, Ramasamy S, Bindroo B, Naik V (2014) STRUCTURE PLOT: a program for drawing elegant STRUCTURE bar plots in user friendly interface. SpringerPlus 3:431

Reding DM, Bronikowski AM, Johnson WE, Clark WR (2012) Pleistocene and ecological effects on continental-scale genetic differentiation in the bobcat (Lynx rufus). Mol Ecol 21:3078-3093

Riley SPD (2006) Spatial ecology of Bobcats and Gray Foxes in urban and rural zones of a national park. J Wildl Manage 70:1425-1435

Riley SPD, Foley J, Chomel B (2004) Exposure to feline and canine pathogens in bobcats and gray foxes in urban and rural zones of a national park in California. J Wildl Dis 40:11-22

Riley SPD, Pollinger JP, Sauvajot RM, York EC, Bromley C, Fuller TK, Wayne RK (2006) A Southern California freeway is a physical and social barrier to gene flow in carnivores. Mol Ecol 15:1733-1741

Riley SPD, Sauvajot RM, Fuller TK, York EC, Kamradt DA, Bromley C, Wayne RK (2003) Effects of urbanization and habitat fragmentation on bobcats and coyotes in Southern California. Conserv Biol 17:566-576

Riley SPD, Serieys LEK, Pollinger JP, Sikich JA, Dalbeck L, Wayne RK, Ernest HB (2014) Individual behaviors dominate the dynamics of an urban mountain lion population isolated by roads. Curr Biol 24:1989-1994 
Rodriguez A, Crema G, Delibes M (1996) Use of Non-Wildlife Passages Across a High Speed Railway by Terrestrial Vertebrates. J Appl Ecol 33:1527

Roelke ME, Martenson JS, O'Brien SJ (1993) The consequences of demographic reduction and genetic depletion in the endangered Florida panther. Curr Biol 3:340-350

Ruell EW, Riley SPD, Douglas MR, Antolin MF, Pollinger JR, Tracey JA, Lyren LM, Boydston EE, Fisher RN, Crooks KR (2012) Urban Habitat fragmentation and genetic population structure of bobcats in coastal Southern California. Am Midland Nat 168:265-280

Ruell EW, Riley SPD, Douglas MR, Pollinger JP, Crooks KR (2009) Estimating Bobcat population sizes and densities in a fragmented urban landscape using noninvasive capturerecapture sampling. J Mammal 90:129-135

Saccheri I, Kuussaari M, Kankare M, Vikman P, Fortelius W, Hanski I (1998) Inbreeding and extinction in a butterfly metapopulation. Nature 392:491-494

Serieys LEK, Armenta TC, Moriarty JG, Boydston EE, Lyren LM, Poppenga RH, Crooks KR, Wayne RK, Riley SPD (2015a) Anticoagulant rodenticides in urban bobcats: exposure, risk factors and potential effects based on a 16-year study. Ecotoxicology 24:844-862

Serieys LEK, Lea A, Pollinger JP, Riley SPD, Wayne RK (2015b) Disease and freeways drive genetic change in urban bobcat populations. Evol Appl 8:75-92

Sleater-Squires S (2016) Pedigree reconstruction sheds light on the mating system and social dynamics of urban Bobcats (Lynx rufus). University of California, Los Angeles

Soulé ME, Alberts AC, Bolger DT, Soule ME (1992) The effects of habitat fragmentation on chaparral plants and vertebrates. Oikos 63:39

Stillfried M, Fickel J, Börner K, Wittstatt U, Heddergott M, Ortmann S, Kramer-Schadt S, Frantz AC (2017) Do cities represent sources, sinks or isolated islands for urban wild boar population structure? J Appl Ecol 54:272-281

Tammeleht E, Remm J, Korsten M, Davison J, Tumanov I, Saveljev A, Männil P, Kojola I, Saarma U (2010) Genetic structure in large, continuous mammal populations: The example of brown bears in northwestern Eurasia. Mol Ecol 19:5359-5370

Taylor PD, Fahrig L, Henein K, Merriam G (1993) Connectivity is a vital element of landscape structure. Oikos 68:571-573

Tischendorf L, Fahrig L (2000) On the usage and measurement of landscape connectivity. Oikos 90:7-19

Turner MG (1989) Landscape ecology: the effect of pattern on process. Annu Rev Ecol Syst 20:171-197

Vandergast AG, Lewallen EA, Deas J, Bohonak AJ, Weissman DB, Fisher RN (2009) Loss of genetic connectivity and diversity in urban microreserves in a southern California endemic Jerusalem cricket (Orthoptera: Stenopelmatidae: Stenopelmatus n. sp. "santa monica"). J Insect Conserv 13:329-345

van Etten J (2017) R package gdistance: Distances and routes on geographical grids. J Stat Softw 76:1-21

Verboom J, Lankester K, Metz JAJ (1991) Linking local and regional dynamics in stochastic metapopulation models 12:39-55

Zeller KA, McGarigal K, Beier P, Cushman SA, Vickers TW, Boyce WM (2014) Sensitivity of landscape resistance estimates based on point selection functions to scale and behavioral state: Pumas as a case study. Landscape Ecol 29:541-557

Zeller KA, Vickers TW, Ernest HB, Boyce WM (2017) Multilevel, multi-scale resource selection functions and resistance surfaces for conservation planning: Pumas as a case study. PLoS ONE 12:e0179570

Zoutendyk MD, David Mayer M, Zoutendyk DM, Mayer M (2013) 2012 MSCP annual report

Publisher's Note Springer Nature remains neutral with regard to jurisdictional claims in published maps and institutional affiliations. 


\section{Supplemental Tables and Figures}
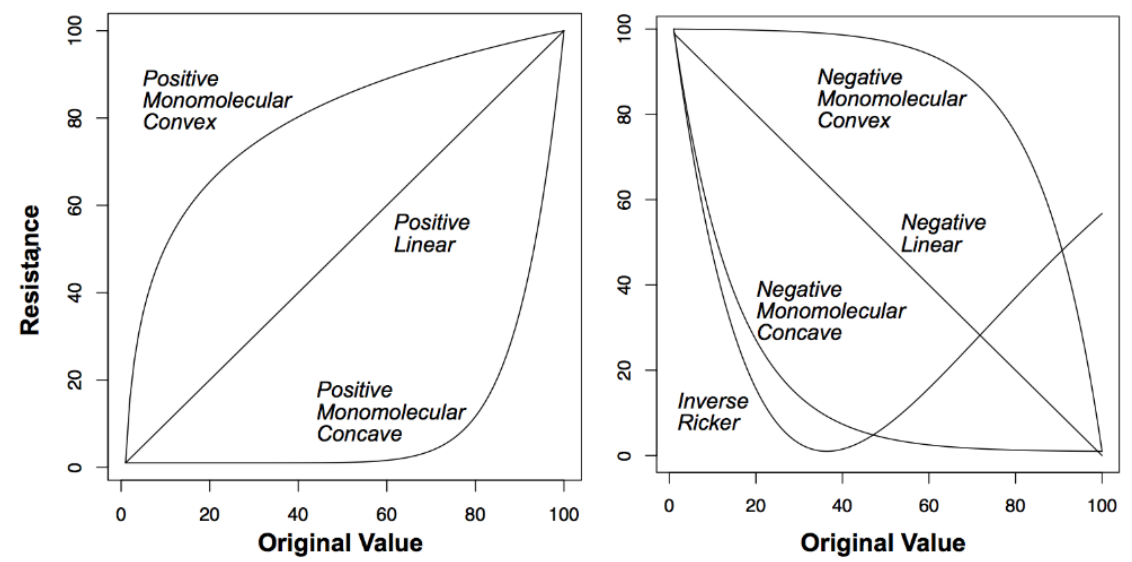

Figure S1. Functions used to transform the environmental variables to resistance, with a range of 1-100, for use in the landscape genetic analysis. Figure adapted from Zeller et al. (2017). 
Table S1: Microsatellite sources. List of the 19 Microsatellite Markers Used to Genotype bobcats in this study. Loci denoted by "a" represent the 11 loci used in the "11 loci" dataset.

\begin{tabular}{llcc}
\hline Locus & Species & Repeat & Chromosome \\
\hline \multicolumn{2}{c}{ Menotti-Raymond et al. 1999 } & di & A1 \\
FCA008 & Domestic Cat & di & B1 \\
FCA023 & Domestic Cat & di & D3 \\
FCA026 & Domestic Cat & di & E3 \\
FCA031 & Domestic Cat & di & C2 \\
FCA043 & Domestic Cat & di & A1 \\
FCA045 & Domestic Cat & di & C2 \\
FCA077 & Domestic Cat & di & E1 \\
FCA082 & Domestic Cat & di & A1 \\
FCA090 & Domestic Cat & di & A2 \\
FCA096 & Domestic Cat & di & D3 \\
FCA132 & Domestic Cat & di & B1 \\
FCA149 & Domestic Cat & tetra & B1 \\
FCA559 & Domestic Cat & & \\
\hline Menotti-Raymond et al. 2005 & tetra & D4 \\
FCA742 & Domestic Cat & & \\
\hline Faircloth et al. 2005 & tetra & Unknown \\
BCD8T & Bobcat & tetra & Unknown \\
BCE5T & Bobcat & di & Unknown \\
BCG8T & Bobcat & & \\
\hline Carmichael et al. 2000 & di & Unknown \\
Lc110 & Lynx & di & Unknown \\
Lc111 & Lynx & & \\
\hline
\end{tabular}


Table S2: 11 loci microsatellite summary by locus (n=422). Hardy-Weinberg Equilibrium (HWE) value corrected p-values for BY (Benjamini-Yekutieli, Benjamini and Yekutieli 2001) were calculated using the p.adjust function in the stats package in $\mathrm{R}$. $\mathrm{H}_{\mathrm{O}}=$ Observed Heterozygosity. $\mathrm{H}_{\mathrm{E}}=$ Expected Heterozygosity.

\begin{tabular}{|c|c|c|c|c|c|c|c|}
\hline & $\begin{array}{l}\text { Number } \\
\text { Genotyped }\end{array}$ & $\begin{array}{l}\text { Number of } \\
\text { Alleles }\end{array}$ & $\begin{array}{l}\text { Proportion } \\
\text { of Unique } \\
\text { Alleles }\end{array}$ & $\mathrm{Ho}_{\mathrm{O}}$ & $\mathrm{H}_{\mathrm{E}}$ & $\begin{array}{l}\text { HWE (p- } \\
\text { value) }\end{array}$ & $\begin{array}{l}\text { HWE (p- } \\
\text { values with } \\
\text { BY } \\
\text { correction) }\end{array}$ \\
\hline FCA 008 & 422 & 10 & 0 & 0.71 & 0.77 & 0.02 & 0.11 \\
\hline FCA 023 & 421 & 7 & 0.14 & 0.75 & 0.74 & 0.06 & 0.24 \\
\hline FCA 026 & 422 & 15 & 0 & 0.78 & 0.88 & 0 & 0 \\
\hline FCA 031 & 421 & 8 & 0 & 0.75 & 0.81 & 0 & 0.01 \\
\hline FCA 043 & 421 & 5 & 0 & 0.72 & 0.75 & 0.04 & 0.11 \\
\hline FCA 096 & 420 & 14 & 0.21 & 0.69 & 0.76 & 0 & 0.01 \\
\hline FCA 132 & 419 & 9 & 0 & 0.71 & 0.80 & 0 & 0 \\
\hline FCA 149 & 419 & 9 & 0 & 0.77 & 0.83 & 0 & 0 \\
\hline FCA 559 & 420 & 6 & 0 & 0.65 & 0.63 & 0.01 & 0.06 \\
\hline FCA 742 & 422 & 7 & 0.14 & 0.63 & 0.66 & 0.11 & 0.31 \\
\hline BCE5T & 421 & 7 & 0.14 & 0.67 & 0.71 & 0 & 0 \\
\hline
\end{tabular}

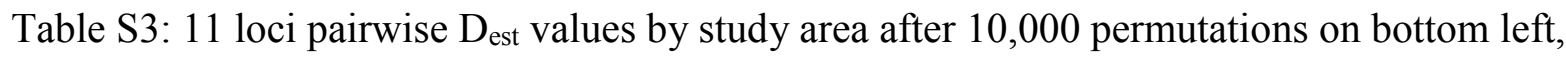
respective p-values on upper right. Golden Gate National Recreation Area (GG), Los Angeles Counties (LA), Orange County (OC), San Diego (SD), and San Jose (SJ).

\begin{tabular}{llllll}
\hline & GG & LA & OC & SD & SJ \\
\hline GG & NA & $<0.00$ & 0.11 & $<0.00$ & $<0.00$ \\
LA & 0.17 & NA & $<0.00$ & $<0.00$ & 0.14 \\
OC & 0.01 & 0.05 & NA & $<0.00$ & $<0.00$ \\
SD & 0.14 & 0.06 & 0.03 & NA & $<0.00$ \\
SJ & 0.17 & 0.01 & 0.09 & 0.11 & NA \\
\hline
\end{tabular}


Table S4: 19 loci microsatellite summary by locus $(\mathrm{n}=118)$. Hardy-Weinberg Equilibrium (HWE) value corrected p-values for BY (Benjamini-Yekutieli, Benjamini and Yekutieli 2001) were calculated using the p.adjust function in the stats package in $\mathrm{R} . \mathrm{H}_{\mathrm{O}}=$ Observed Heterozygosity. $\mathrm{H}_{\mathrm{E}}=$ Expected Heterozygosity.

\begin{tabular}{|c|c|c|c|c|c|c|c|}
\hline & $\begin{array}{l}\text { Number } \\
\text { Genotyped }\end{array}$ & $\begin{array}{l}\text { Number of } \\
\text { Alleles }\end{array}$ & $\begin{array}{l}\text { Proportion } \\
\text { of Unique } \\
\text { Alleles }\end{array}$ & $\mathrm{Ho}_{\mathrm{O}}$ & $\mathrm{H}_{\mathrm{E}}$ & $\begin{array}{l}\text { HWE } \\
\text { (p- } \\
\text { value) }\end{array}$ & $\begin{array}{l}\text { HWE (p- } \\
\text { values with } \\
\text { BY } \\
\text { correction) }\end{array}$ \\
\hline FCA 008 & 115 & 10 & 0.1 & 0.73 & 0.78 & 0.82 & 1 \\
\hline FCA 023 & 117 & 5 & 0 & 0.68 & 0.74 & 0.10 & 0.67 \\
\hline FCA 026 & 112 & 14 & 0 & 0.82 & 0.88 & 0.02 & 0.20 \\
\hline FCA 031 & 117 & 8 & 0 & 0.73 & 0.82 & 0 & 0.04 \\
\hline FCA 043 & 108 & 6 & 0.17 & 0.77 & 0.78 & 0.1 & 0.59 \\
\hline FCA 045 & 100 & 10 & 0.3 & 0.58 & 0.84 & 0 & 0 \\
\hline FCA 077 & 113 & 7 & 0.14 & 0.71 & 0.74 & 0.05 & 0.37 \\
\hline FCA 082 & 113 & 10 & 0 & 0.76 & 0.82 & 0.01 & 0.05 \\
\hline FCA 090 & 116 & 8 & 0 & 0.61 & 0.73 & 0 & 0.04 \\
\hline FCA 096 & 111 & 12 & 0.17 & 0.67 & 0.79 & 0.02 & 0.12 \\
\hline FCA 132 & 103 & 8 & 0 & 0.78 & 0.84 & 0.21 & 1 \\
\hline FCA 149 & 115 & 9 & 0 & 0.81 & 0.84 & 0.14 & 0.95 \\
\hline FCA 559 & 117 & 6 & 0.5 & 0.62 & 0.61 & 0.75 & 1 \\
\hline FCA 742 & 118 & 7 & 0.14 & 0.64 & 0.69 & 0.16 & 0.95 \\
\hline Lc 110 & 115 & 7 & 0.14 & 0.67 & 0.68 & 0.9 & 1 \\
\hline Lc 111 & 112 & 8 & 0 & 0.71 & 0.74 & 0.39 & 1 \\
\hline BCE5T & 115 & 7 & 0 & 0.69 & 0.72 & 0.54 & 1 \\
\hline BCD8T & 118 & 7 & 0.14 & 0.31 & 0.34 & 0.18 & 0.95 \\
\hline BCG8T & 118 & 14 & 0.14 & 0.84 & 0.85 & 0.01 & 0.09 \\
\hline
\end{tabular}

Table S5: 19 loci pairwise $\mathrm{D}_{\text {est }}$ values by study area after 10,000 permutations on bottom left, respective p-values on upper right. Golden Gate National Recreation Area (GG), Los Angeles Counties (LA), Orange County (OC), San Diego (SD), and San Jose (SJ).

\begin{tabular}{llllll}
\hline & GG & LA & OC & SD & SJ \\
\hline GG & NA & 0.13 & $<0.00$ & $<0.00$ & $<0.00$ \\
LA & 0.02 & NA & $<0.00$ & $<0.00$ & $<0.00$ \\
OC & 0.19 & 0.08 & NA & $<0.00$ & $<0.00$ \\
SD & 0.19 & 0.08 & 0.05 & NA & $<0.00$ \\
SJ & 0.16 & 0.10 & 0.09 & 0.08 & NA \\
\hline
\end{tabular}


Figure S2: Population graph based on a graph theoretic approach for six subpopulations (GG, SJ, LA, OCC, OCI, and SD) using the 11 loci dataset. Node size indicates degree of connectivity while edges represent genetic distance among subpopulations with significant genetic similarity.

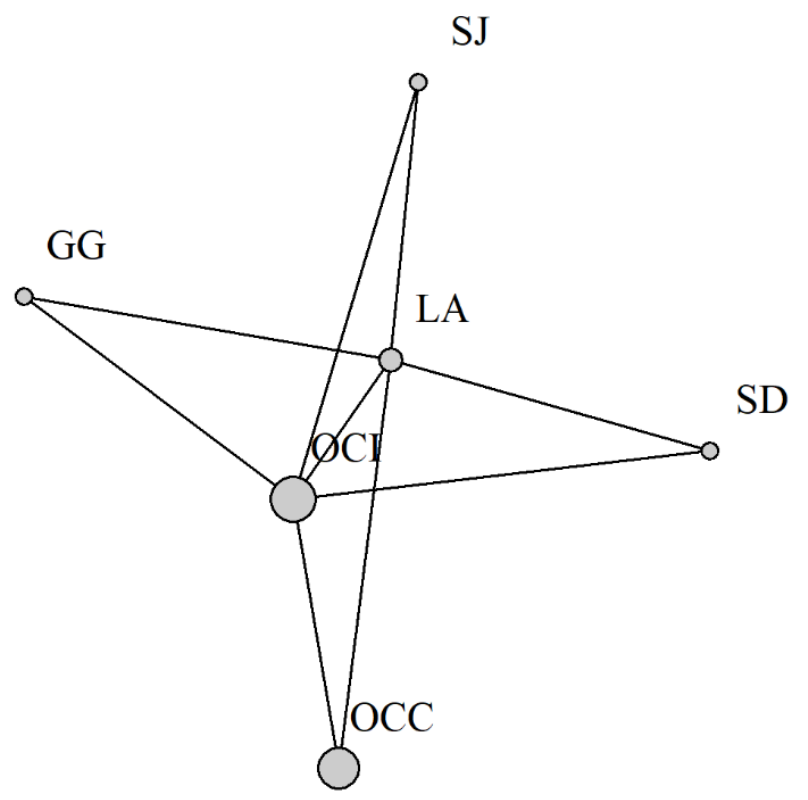


Table S6. Landscape analysis resistance summary showing each variable, the selected scale, and transformation (based on AIC $\mathrm{c}_{\mathrm{c}}$ ), as well as marginal and conditional $\mathrm{R}^{2}$ values. Both DPS (top) and Nei's distance (bottom) were used the genetic distance response variable to test environmental variables with the greatest degree of explanatory power for the observed patterns of genetic structuring among bobcats in southern California. A positive sign indicates preference for a given variable and minus avoidance whereas the inverse Ricker function indicates lowest resistance at middle values and high resistance at the tails of the original variable values.

\begin{tabular}{|c|c|c|c|c|c|c|c|}
\hline Variable & Scale (m) & Transformation & Sign & $\mathbf{A I C}_{\mathbf{C}}$ & $\Delta \mathbf{A I C}_{\mathbf{C}}$ & $\operatorname{Marg} \mathbf{R}^{2}$ & Cond $\mathbf{R}^{2}$ \\
\hline \multicolumn{8}{|c|}{$D_{P S}$} \\
\hline Permeability & 2000 & Inverse Ricker & 1 & -9392.05 & 0 & 0.152 & 0.360 \\
\hline Impervious & 275 & Pos. monomolecular convex & + & -9383.95 & 8.096 & 0.150 & 0.356 \\
\hline Traffic density & 2000 & Pos. monomolecular convex & + & -9333.31 & 58.74 & 0.116 & 0.297 \\
\hline Road density & 275 & Pos. monomolecular convex & + & -9319.4 & 72.645 & 0.101 & 0.277 \\
\hline Distance to urban & 4000 & Inverse Ricker & l & -9187.22 & 204.827 & 0.061 & 0.216 \\
\hline Euclidean distance & & & & -9182.56 & 209.487 & 0.059 & 0.214 \\
\hline \multicolumn{8}{|c|}{ Nei's Distance } \\
\hline Permeability & 2000 & Inverse Ricker & 1 & -453.507 & 0.000 & 0.089 & 0.318 \\
\hline Impervious & 1000 & Positive linear & + & -450.25 & 3.257 & 0.077 & 0.297 \\
\hline Traffic density & 1000 & Pos. monomolecular convex & + & -434.578 & 18.929 & 0.072 & 0.280 \\
\hline Road density & 1000 & Pos. monomolecular convex & + & -432.705 & 20.802 & 0.060 & 0.269 \\
\hline Distance to urban & 170 & Positive linear & + & -383.56 & 69.947 & 0.046 & 0.240 \\
\hline Euclidean distance & & & & -380.881 & 72.626 & 0.045 & 0.241 \\
\hline
\end{tabular}


Table S7. Landscape analysis resistance summary for each of four subpopulations showing each variable, the selected scale, and transformation (based on $\mathrm{AIC}_{\mathrm{c}}$ ), as well as marginal and conditional $\mathrm{R}^{2}$ values. Both $\mathrm{DPS}_{\mathrm{PS}}$ (top) and Nei's distance (bottom) were used the genetic distance response variable to test environmental variables with the greatest degree of explanatory power for the observed patterns of genetic structuring among bobcats in southern California. A positive sign indicates preference for a given variable and minus avoidance whereas the inverse Ricker function indicates lowest resistance at middle values and high resistance at the tails of the original variable values.

\begin{tabular}{|c|c|c|c|c|c|c|c|c|}
\hline Subpop & Variable & Scale (m) & Transformation & Sign & $\mathbf{A I C}_{\mathbf{C}}$ & $\Delta \mathbf{A I C}_{\mathbf{C}}$ & $\begin{array}{c}\text { Marg } \\
\mathbf{R}^{2} \\
\end{array}$ & $\begin{array}{c}\text { Cond } \\
\mathbf{R}^{2} \\
\end{array}$ \\
\hline \multirow{14}{*}{$\mathbf{L A}$} & \multicolumn{8}{|c|}{$D_{P S}$} \\
\hline & Euclidean distance & & & & -283.623 & 0.000 & 0.064 & 0.216 \\
\hline & Road density & 2000 & Inverse Ricker & / & -277.82 & 5.803 & 0.017 & 0.165 \\
\hline & Distance to urban & 170 & Pos. monomolecular convex & + & -277.348 & 6.275 & 0.008 & 0.165 \\
\hline & Traffic density & 2000 & Inverse Ricker & l & -277.290 & 6.333 & 0.007 & 0.163 \\
\hline & Permeability & 170 & Pos. monomolecular concave & + & -277.266 & 6.357 & 0.009 & 0.167 \\
\hline & Impervious & 170 & Neg. monomolecular concave & - & -277.253 & 6.370 & 0.008 & 0.165 \\
\hline & \multicolumn{8}{|c|}{ Nei's distance } \\
\hline & Euclidean distance & & & & 35.445 & 0.000 & 0.050 & 0.242 \\
\hline & Road density & 2000 & Inverse Ricker & / & 40.228 & 4.783 & 0.009 & 0.192 \\
\hline & Impervious & 2000 & Pos. monomolecular convex & + & 40.302 & 4.856 & 0.005 & 0.196 \\
\hline & Traffic density & 3000 & Positive linear & + & 40.359 & 4.914 & 0.005 & 0.200 \\
\hline & Permeability & 519 & Negative linear & - & 40.467 & 5.022 & 0.003 & 0.195 \\
\hline & Distance to urban & 170 & Pos. monomolecular convex & + & 40.593 & 5.148 & 0.002 & 0.193 \\
\hline \multirow{10}{*}{ OCC } & \multicolumn{8}{|c|}{$D_{P S}$} \\
\hline & Road density & 2000 & Pos. monomolecular concave & + & -282.871 & 0.000 & 0.062 & 0.457 \\
\hline & Permeability & 4000 & Inverse Ricker & / & -282.218 & 0.653 & 0.029 & 0.462 \\
\hline & Traffic density & 2000 & Positive linear & + & -281.739 & 1.133 & 0.060 & 0.450 \\
\hline & Impervious & 2000 & Pos. monomolecular concave & + & -280.942 & 1.929 & 0.035 & 0.449 \\
\hline & Distance to urban & 170 & Pos. monomolecular convex & + & -280.286 & 2.585 & 0.021 & 0.463 \\
\hline & Euclidean distance & & & & -279.213 & 3.658 & 0.017 & 0.459 \\
\hline & \multicolumn{8}{|c|}{ Nei's distance } \\
\hline & Road density & 2000 & Inverse Ricker & 1 & 25.998 & 0.000 & 0.029 & 0.480 \\
\hline & Traffic density & 2000 & Positive Linear & + & 26.097 & 0.100 & 0.030 & 0.471 \\
\hline
\end{tabular}




\begin{tabular}{|c|c|c|c|c|c|c|c|c|}
\hline Subpop & Variable & Scale (m) & Transformation & Sign & $\mathbf{A I C}_{\mathbf{C}}$ & $\Delta \mathrm{AIC}_{\mathbf{C}}$ & $\begin{array}{c}\text { Marg } \\
\mathbf{R}^{2} \\
\end{array}$ & $\begin{array}{c}\text { Cond } \\
\mathbf{R}^{2} \\
\end{array}$ \\
\hline & Permeability & 2000 & Inverse Ricker & / & 26.129 & 0.131 & 0.040 & 0.484 \\
\hline & Impervious & 519 & Positive Linear & + & 26.292 & 0.295 & 0.029 & 0.481 \\
\hline & Distance to urban & 170 & Inverse Ricker & / & 28.481 & 2.483 & 0.002 & 0.488 \\
\hline & Euclidean distance & & & & 28.559 & 2.561 & 0.002 & 0.488 \\
\hline \multirow{14}{*}{ OCI } & \multicolumn{8}{|c|}{$D_{P S}$} \\
\hline & Permeability & 2000 & Pos. monomolecular convex & + & -426.070 & 0.000 & 0.040 & 0.144 \\
\hline & Impervious & 2000 & Neg. monomolecular concave & - & -425.095 & 0.975 & 0.035 & 0.136 \\
\hline & Road density & 2000 & Neg. monomolecular concave & - & -425.081 & 0.989 & 0.033 & 0.136 \\
\hline & Distance to urban & 2000 & Pos. monomolecular convex & + & -423.969 & 2.102 & 0.020 & 0.125 \\
\hline & Traffic density & 3000 & Neg. monomolecular concave & - & -423.549 & 2.521 & 0.024 & 0.130 \\
\hline & Euclidean distance & & & & -421.792 & 4.279 & 0.004 & 0.122 \\
\hline & \multicolumn{8}{|c|}{ Nei's distance } \\
\hline & Permeability & 2000 & Pos. monomolecular convex & + & 36.401 & 0.000 & 0.040 & 0.146 \\
\hline & Impervious & 2000 & Neg. monomolecular concave & - & 37.090 & 0.689 & 0.038 & 0.141 \\
\hline & Road density & 2000 & Neg. monomolecular concave & - & 37.516 & 1.115 & 0.032 & 0.140 \\
\hline & Distance to urban & 1000 & Pos. monomolecular convex & + & 38.511 & 2.110 & 0.019 & 0.131 \\
\hline & Traffic density & 3000 & Neg. monomolecular concave & - & 39.152 & 2.751 & 0.022 & 0.135 \\
\hline & Euclidean distance & & & & 40.780 & 4.379 & 0.003 & 0.126 \\
\hline \multirow{11}{*}{ SD } & \multicolumn{8}{|c|}{$D_{P S}$} \\
\hline & Permeability & 170 & Inverse Ricker & / & -1154.64 & 0.000 & 0.071 & 0.207 \\
\hline & Impervious & 170 & Positive Linear & + & -1151.66 & 2.989 & 0.057 & 0.192 \\
\hline & Road density & 170 & Pos. monomolecular convex & + & -1147.97 & 6.679 & 0.029 & 0.160 \\
\hline & Traffic density & 275 & Pos. monomolecular convex & + & -1146.94 & 7.703 & 0.030 & 0.147 \\
\hline & Distance to urban & 4000 & Inverse Ricker & I & -1140.33 & 14.319 & 0.009 & 0.128 \\
\hline & Euclidean distance & & & & -1140.16 & 14.485 & 0.009 & 0.128 \\
\hline & \multicolumn{8}{|c|}{ Nei's distance } \\
\hline & Permeability & 170 & Inverse Ricker & 1 & -145.666 & 0.000 & 0.062 & 0.221 \\
\hline & Impervious & 170 & Positive Linear & + & -142.415 & 3.251 & 0.047 & 0.209 \\
\hline & Traffic density & 275 & Pos. monomolecular convex & + & -138.048 & 7.618 & 0.024 & 0.176 \\
\hline
\end{tabular}




\begin{tabular}{|c|c|c|c|c|c|c|c|c|}
\hline Subpop & Variable & Scale (m) & Transformation & Sign & $\mathrm{AIC}_{\mathbf{C}}$ & $\Delta \mathrm{AIC}_{\mathrm{C}}$ & $\begin{array}{c}\text { Marg } \\
\mathbf{R}^{2}\end{array}$ & $\begin{array}{c}\text { Cond } \\
\mathbf{R}^{2} \\
\end{array}$ \\
\hline & Road density & 170 & Positive Linear & + & -137.967 & 7.699 & 0.021 & 0.185 \\
\hline & Distance to urban & 4000 & Inverse Ricker & / & -132.710 & 12.955 & 0.008 & 0.170 \\
\hline & Euclidean distance & & & & -132.641 & 13.025 & 0.008 & 0.170 \\
\hline
\end{tabular}


Appendix 1.

Microsatellite Amplification and validation

For all loci, the reverse primers were not altered from the original published sequence (Table S1), whereas the forward primers were modified to contain the 16-bp M13 sequence (-20: 5'-GTA AAA CGA CGG CCA G-3') at the 5' end. The PCR products were fluorescently labeled during the PCR reaction using a second forward primer comprised of the above M13 sequence along with the dye-label 6-FAM (Applied Biosystems, Foster City, CA, USA). PCR reactions were performed in $10 \mu \mathrm{L}$ volumes, consisting of $1.0 \mu \mathrm{L}$ M13 hybrid primer mix, $2.1 \mu \mathrm{L}$ distilled water, $0.4 \mu \mathrm{L} 10 \mathrm{mg} / \mathrm{mL}$ bovine serum albumin, $5.0 \mu \mathrm{L}$ QIAGEN multiplex PCR master mix, and $1.5 \mu \mathrm{L}(20-50 \mathrm{ng})$ extracted DNA. PCR amplifications were implemented under the following thermocycling profile: initial activation at $95^{\circ} \mathrm{C}$ for $15 \mathrm{~min}$; followed by 25 cycles of denaturation at $94^{\circ} \mathrm{C}$ for $30 \mathrm{~s}$, annealing at $59^{\circ} \mathrm{C}$ for $90 \mathrm{~s}$, and elongation at $72^{\circ} \mathrm{C}$ for $60 \mathrm{~s}$; then 15 cycles at $94^{\circ} \mathrm{C}$ for $30 \mathrm{~s}, 53^{\circ} \mathrm{C}$ for $90 \mathrm{~s}$, and $72^{\circ} \mathrm{C}$ for $60 \mathrm{~s}$ with a final extension step of $60^{\circ} \mathrm{C}$ for $30 \mathrm{~min}$ (Sleater-Squires 2016). Finally, $9.7 \mu \mathrm{L}$ Hi-Di formamide and 0.3 $\mu \mathrm{L}$ GeneScanTM 500 LIZ ${ }^{\circledR}$ Size Standard were added to a 1:20 dilution of the PCR product (Sleater-Squires 2016) and analyzed using an ABI model 3730 DNA Sequencer with the XL Upgrade (Thermo Fisher Scientific, Waltham, MA, USA). Resulting peaks were then scored using PeakScanner version 2 (Thermo Fisher Scientific, Waltham, MA, USA).

The allelic scores from these validated samples were then compared to the allelic scores they originally received, and the difference was calculated for each individual at each locus. Loci where the difference between the validation and original alleles was a consistent number of base pairs across all individuals from a study region were classified as "clean shifts". These "clean shifts" are indicative of small changes between laboratories due to different protocols, addition of M13 tails (for multiplexing), or various equipment and materials (Ellis et al. 2011). We excluded animals who did not have at least two-thirds of their alleles amplify.

The types of errors we encountered during the validation of this combined dataset included typographical errors, scoring inconsistencies and standardization, and size shifts (Ellis et al. 2011). Generally, scoring practices were similar and consistent among all labs. Because the validation was conducted in the same lab and under similar protocols to the original LA data, the LA validation individuals had, in most cases, the exact base pairs (bp) from their original peak scoring and the current peak scoring. OC had mostly similar values $( \pm 1)$ even though they were run at Colorado State University (CSU). The clean shifts from the SD samples had larger differences (up to $19 \mathrm{bp}$ ) likely owing to the addition of the M13 tails to the primers in the validation runs as opposed to the original sequence from Menotti-Raymond et al. (1999).

References 
Benjamini, Y., and Yekutieli, D. (2001). The control of the false discovery rate in multiple testing under dependency. Annals of Statistics, 29, 1165-1188. doi: 10.1214/aos/1013699998.

Carmichael LE, Clark W, Strobeck C. 2000. Development and characterization of microsatellite loci from lynx (Lynx canadensis), and their use in other felids. Mol. Ecol. 9(12): 2197-2199.

Faircloth BC, Reid A, Valentine T, Eo SH, Terhune TM, Glenn TC, Palmer WE, Nairn CJ, Carroll JP. 2005. Tetranucleotide, trinucleotide, and dinucleotide loci from the bobcat (Lynx rufus). Mol. Ecol. Notes 5(2): 387-389.

Menotti-Raymond, M., V. A. David, L. A. Lyons, A. A. Schä, J. F. Tomlin, M. K. Hutton, S. J. O 'brien, A. A. Schäffer, J. F. Tomlin, M. K. Hutton, and S. J. O'Brien. 1999. A Genetic Linkage Map of Microsatellites in the Domestic Cat (Felis catus). Genomics 57:9-23.

Menotti-Raymond, M.A., David, V.A., Wachter, L.L., Butler, J.M. and O'Brien, S.J., 2005. An STR forensic typing system for genetic individualization of domestic cat (Felis catus) samples. Journal of Forensic Science, 50(5):JFS2004317-10. 